\title{
Relationships between milk yield and somatic cell score in Canadian Holsteins from simultaneous and recursive random regression models
}

\author{
J. Jamrozik, ${ }^{1}$ J. Bohmanova, and L. R. Schaeffer \\ Centre for Genetic Improvement of Livestock, Department of Animal and Poultry Science, University of Guelph, Guelph, Ontario, \\ Canada, N1G 2W1
}

\begin{abstract}
Multiple-trait random regression animal models with simultaneous and recursive links between phenotypes for milk yield and somatic cell score (SCS) on the same test day were fitted to Canadian Holstein data. All models included fixed herd test-day effects and fixed regressions within region-age at calving-season of calving classes, and animal additive genetic and permanent environmental regressions with random coefficients. Regressions were Legendre polynomials of order 4 on a scale from 5 to $305 \mathrm{~d}$ in milk (DIM). Bayesian methods via Gibbs sampling were used for the estimation of model parameters. Heterogeneity of structural coefficients was modeled across (the first 3 lactations) and within (4 DIM intervals) lactation. Model comparisons in terms of Bayes factors indicated the superiority of simultaneous models over the standard multiple-trait model and recursive parameterizations. A moderate heterogeneous (both across- and within-lactation) negative effect of SCS on milk yield (from -0.36 for 116 to 265 DIM in lactation 1 to -0.81 for 5 to 45 DIM in lactation 3) and a smaller positive reciprocal effect of SCS on milk yield (from 0.007 for 5 to 45 DIM in lactation 2 to 0.023 for 46 to 115 DIM in lactation 3) were estimated in the most plausible specification. No noticeable differences among models were detected for genetic and environmental variances and genetic parameters for the first 2 regression coefficients. The curves of genetic and permanent environmental variances, heritabilities, and genetic and phenotypic correlations between milk yield and SCS on a daily basis were different for different models. Rankings of bulls and cows for 305-d milk yield, average daily SCS, and milk lactation persistency remained the same among models. No apparent benefits are expected from fitting causal phenotypic relationships between milk yield and
\end{abstract}

Received July 23, 2009.

Accepted November 3, 2009.

${ }^{1}$ Corresponding author: jjamrozi@uoguelph.ca
SCS on the same test day in the random regression test-day model for genetic evaluation purposes.

Key words: milk yield, somatic cell score, random regression, structural equation model

\section{INTRODUCTION}

The SCS (concentration of somatic cells) of cow's milk is an economically important trait in dairy cattle because it can be used as an indicator of mammary infection. Multiple-trait models have traditionally been used to infer relationships between milk yield and SCS in applications for genetic evaluation of animals for these traits. One example is the Canadian test-day model (CTDM), in which milk, fat, and protein yields, and SCS in the first 3 lactations are jointly analyzed (Schaeffer et al., 2000). Phenotypic and genetic correlations between milk yield and SCS vary both within and across lactations. In general, phenotypic correlations are negative, whereas genetic correlations display a different sign, depending on lactation number (Samore et al., 2008). The relationships between milk yield and SCS may involve recursive or simultaneous effects that cannot be accounted for properly only by genetic and environmental correlations.

Structural equation models (SEqM; Gianola and Sorensen, 2004) allow for modeling causal pathways between phenotypes. In a 2-trait system (traits X and Y), simultaneous effects refer to the presence of reciprocal direct effects between traits $(\mathrm{X} \rightarrow \mathrm{Y}$ and $\mathrm{X} \leftarrow \mathrm{Y}$, with possible different strengths of associations), whereas recursive effects postulate that one trait affects the other directly $(\mathrm{X} \rightarrow \mathrm{Y}$ or $\mathrm{X} \leftarrow \mathrm{Y}$ ) but that the reciprocal link does not occur.

Phenotypic relationships between milk yield and SCS can be driven by several different mechanisms. An elevated SCS may indicate a bacterial infection of the udder that could have an adverse effect on milk production (infection effect). High-producing cows are more prone to mastitis, which causes higher SCS in the cow's milk (stress effect). On the other hand, higher milk yield may cause a decrease in SCC at the same level 


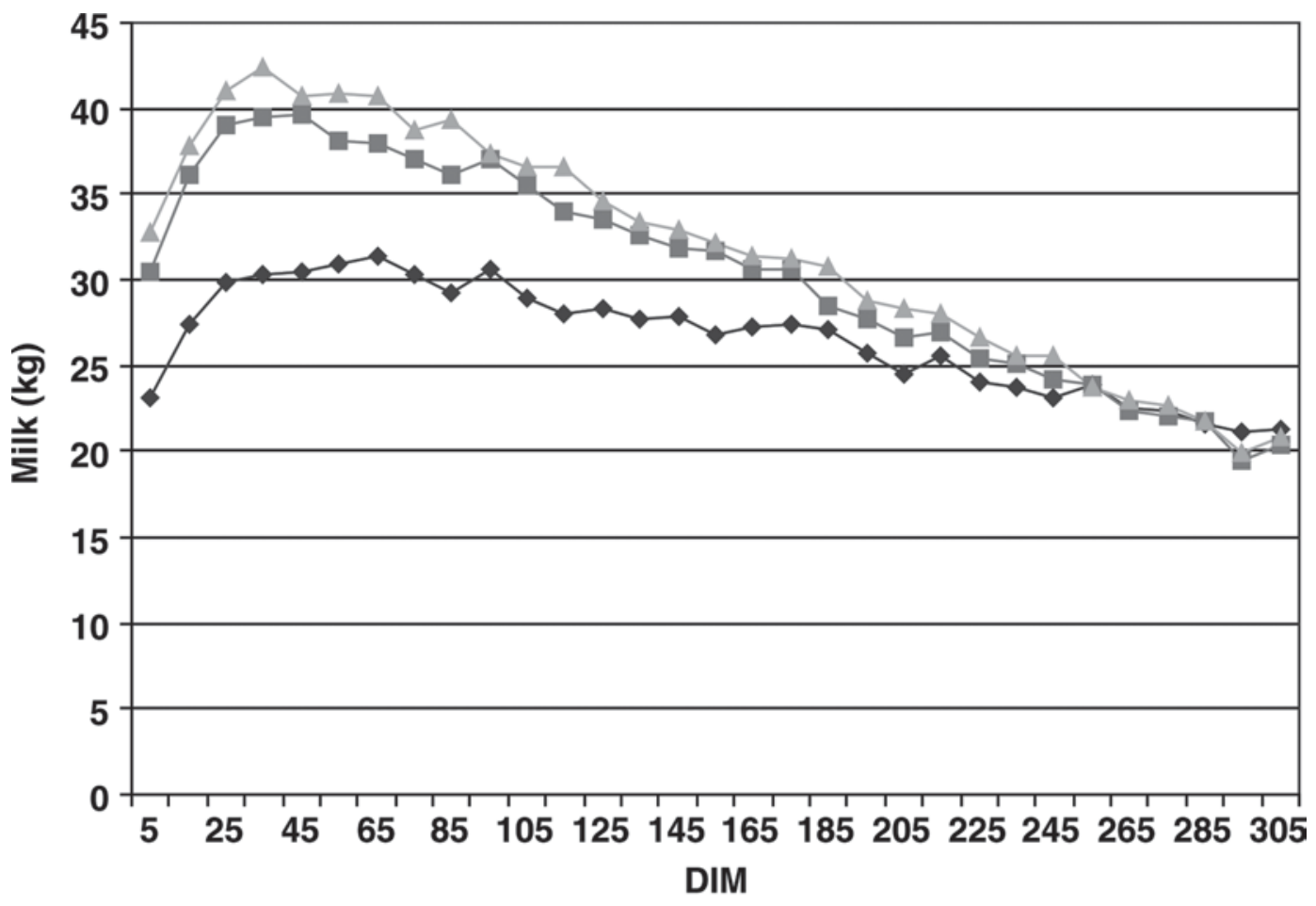

\section{$\rightarrow$ Lactation $1 \rightarrow-$ Lactation $2 \rightarrow$ Lactation 3}

Figure 1. Average lactation curves for milk yield for the first 3 lactations.

of infection (dilution effects), assuming that the SCS is proportional to the degree of infection.

Applications of SEqM in animal breeding, and, in particular, to milk yield and SCS in dairy cattle, have been limited. The models fitted were sire repeatability models that did not fully account for the longitudinal nature of these traits. All published research indicated a negative effect of SCS on milk yield. The negative phenotypic relationship between milk and SCS is more likely caused by an infection effect than by a dilution effect. de los Campos et al. (2006) investigated relationships between SCS and milk yield in the first lactation of Norwegian Red cows. The Bayesian information criterion favored the model with an effect of SCS on milk yield over the 3 other models fitted (i.e., absence of recursive effects, an effect of milk yield on SCS, and simultaneous effects between milk yield and SCS). Wu et al. (2007a) inferred relationships between first-lactation SCS and milk yield in the same population. Results suggested a large negative effect of SCS on milk yield and a small reciprocal effect. The effects were larger in the first $60 \mathrm{~d}$ after calving than in the following $60-\mathrm{d}$ period. Heritability estimates from SEqM were similar to those from the standard mixed model, but some genetic correlations differed considerably among models.
Both studies fitted an effect of clinical mastitis in the model for SCS. Wu et al. (2007b) studied relationships between clinical mastitis and milk yield in 3 periods of the first lactation of Norwegian Red cows by using simultaneous and recursive relationships between these traits. The recursive model suggested a negative within-period effect of liability of clinical mastitis on test-day (TD) milk yield and positive between-period effects of TD milk yield on liability to clinical mastitis in the following period. Estimates of genetic parameters were approximately the same regardless of whether the recursive effects were considered in the model. The results confirmed the unfavorable effect of production on liability to mastitis.

Causal relationships between milk yield and SCS may vary among lactations. They may also show heterogeneity depending on the stage of lactation. If SEqM are deemed superior to the standard multiple-trait models and they could be applied to a routine genetic evaluation, the resulting EBV would be more accurate than the current multiple-trait estimates. The objective of this research was to compare several TD models with random regressions and with different specifications of recursive and simultaneous relationships between the first 3 lactations for milk yield and SCS of Canadian 

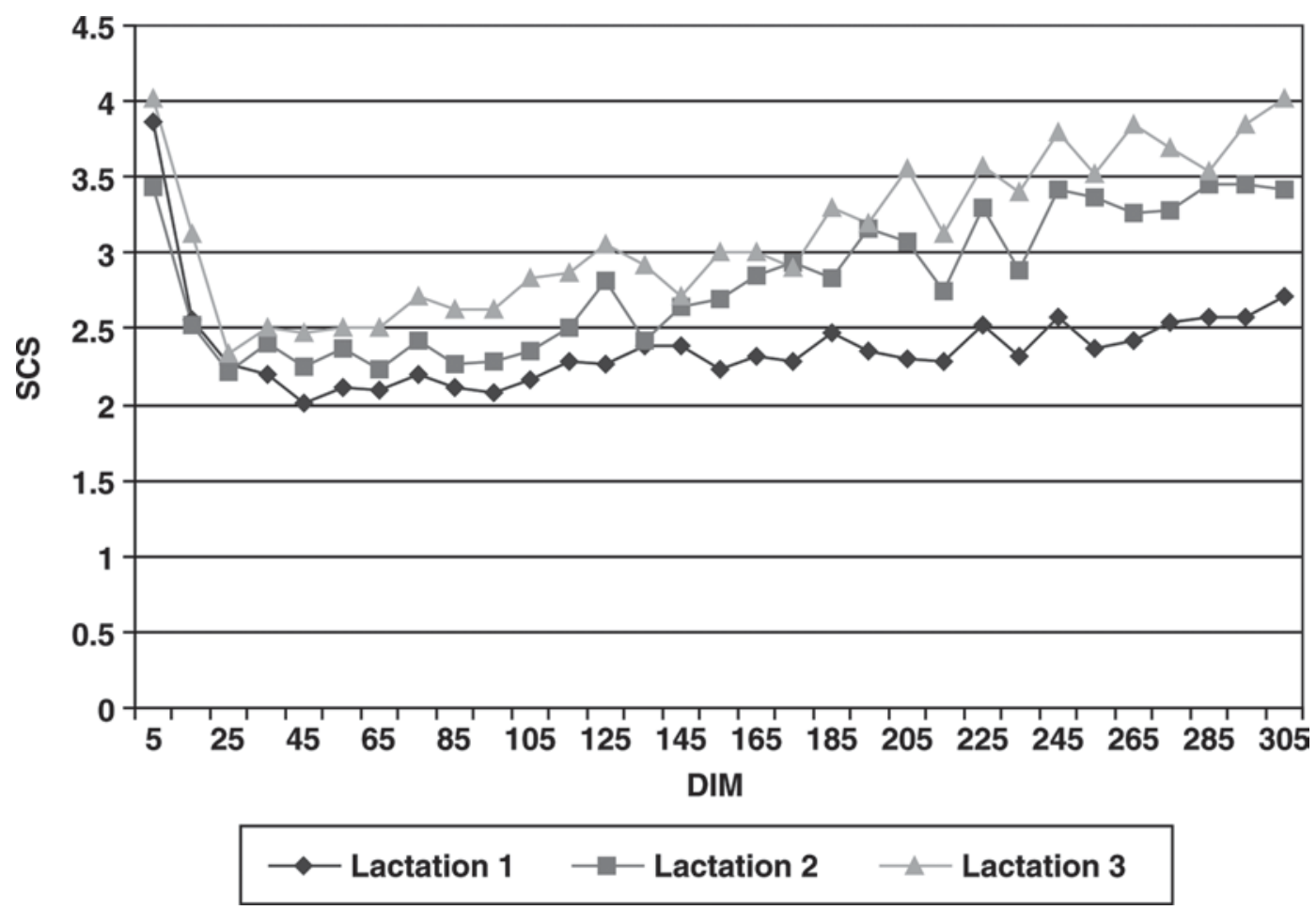

Figure 2. Average lactation curves for SCS for the first 3 lactations.

Holstein cows. Specific objectives included examining between- and within-lactation structural coefficients and comparing genetic parameters and EBV from different models.

\section{MATERIALS AND METHODS}

\section{Data}

Holstein TD data with calving years from 1988 to 2007 were obtained from the Canadian Dairy Network (Guelph, Ontario, Canada) as a subset of the national genetic evaluation data set for production evaluations. The small, computationally manageable data set was a random sample of 59 herds with a minimum of 50 cows each, and with a minimum of 7 TD records per cow. Data were 181,386 TD milk and SCS records from the first 3 lactations of 10,832 cows. The SCS were calculated from SCC as SCS $=\log _{2}(\mathrm{SCC} / 100,000)+3$. Numbers of TD records were $81,118,58,259$, and 42,009 for the first, second, and third lactation, respectively. Days in milk were from 5 to 305. Each cow had both milk yield and SCS recorded on a given TD. Plots of average lactation curves in lactations 1 to 3 are shown in Figures 1 and 2 for milk and SCS, respectively. The number of herd-TD (HTD) classes was 8,424 for the first lactation, 7,897 for the second lactation, and 7,461 for the third lactation. There were 80, 59, and 50 levels of region-age at calving-season of calving classes for the first, second, and third lactations. Pedigree data included 28,557 animals.

\section{Models}

The general form of equations for the SEqM describing milk yield (M) and SCS for the ith cow on the jth $\mathrm{TD}$ in lactation $\mathrm{k}$ can be expressed as

Table 1. Marginal log-likelihood and rank of models based on Bayes factors

\begin{tabular}{lcc}
\hline Model $^{1}$ & Log-likelihood & Rank \\
\hline M-SCS & $-657,427$ & 5 \\
$\mathrm{M} \leftrightarrow$ SCS & $-649,122$ & 2 \\
$\mathrm{M} \leftarrow$ SCS & $-657,524$ & 7 \\
$\mathrm{M} \rightarrow$ SCS & $-657,520$ & 6 \\
$\mathrm{M} \leftrightarrow$ SCS (het) & $-648,973$ & 1 \\
$\mathrm{M} \leftarrow$ SCS (het) & $-657,200$ & 3 \\
$\mathrm{M} \rightarrow$ SCS (het) & $-657,417$ & 4 \\
\hline
\end{tabular}

${ }^{1} \mathrm{M}-\mathrm{SCS}=$ standard multiple-trait model; $\mathrm{M} \leftrightarrow \mathrm{SCS}=$ simultaneous model $\mathrm{M} \leftarrow \mathrm{SCS}=$ model with recursive effect from SCS to milk; $\mathrm{M}$ $\rightarrow$ SCS $=$ model with recursive effect from milk to SCS; M $\leftrightarrow$ SCS (het) = heterogeneous simultaneous model; $\mathrm{M} \leftarrow$ SCS (het) $=$ model with heterogeneous recursive effect from SCS to milk; M $\rightarrow$ SCS (het) $=$ model with heterogeneous recursive effect from milk to SCS. 
Table 2. Estimates of structural coefficients $(\lambda)$ between milk and SCS in 4 DIM intervals ${ }^{1}$ for the first 3 lactations (posterior SD in parentheses), by model

\begin{tabular}{|c|c|c|c|c|c|c|c|c|c|}
\hline \multirow[b]{2}{*}{ Model $^{2}$} & \multirow[b]{2}{*}{ Lactation } & \multicolumn{4}{|c|}{$\lambda_{\mathrm{M} \leftarrow \mathrm{SCS}}$} & \multicolumn{4}{|c|}{$\lambda_{\mathrm{M} \rightarrow \mathrm{SCS}}$} \\
\hline & & 1 & 2 & 3 & 4 & 1 & 2 & 3 & 4 \\
\hline \multirow[t]{3}{*}{$\mathrm{M} \leftrightarrow \mathrm{SCS}$} & 1 & \multicolumn{4}{|c|}{$-0.38(0.022)$} & \multicolumn{4}{|c|}{$0.011(0.003)$} \\
\hline & 2 & \multirow{2}{*}{\multicolumn{4}{|c|}{$\begin{array}{l}-0.52(0.031) \\
-0.68(0.051)\end{array}$}} & \multicolumn{4}{|c|}{$0.009(0.003)$} \\
\hline & 3 & & & \multicolumn{2}{|c|}{$-0.68(0.051)$} & \multicolumn{4}{|c|}{$0.019(0.004)$} \\
\hline \multirow[t]{3}{*}{$\mathrm{M} \leftarrow \mathrm{SCS}$} & 1 & \multirow{2}{*}{\multicolumn{4}{|c|}{$\begin{array}{l}-0.30(0.013) \\
-0.43(0.018)\end{array}$}} & & & & \\
\hline & 2 & & & & & & & & \\
\hline & 3 & \multicolumn{4}{|c|}{$-0.45(0.023)$} & & & & \\
\hline \multirow[t]{3}{*}{$\mathrm{M} \rightarrow \mathrm{SCS}$} & 1 & & & & & \multicolumn{4}{|c|}{$-0.051(0.002)$} \\
\hline & 2 & & & & & & -0.051 & $0.002)$ & \\
\hline & 3 & & & & & & -0.044 & $0.002)$ & \\
\hline \multirow[t]{3}{*}{$\mathrm{M} \leftrightarrow \mathrm{SCS}$ (het) } & 1 & $-0.39(0.034)$ & $-0.47(0.024)$ & $-0.36(0.023)$ & $-0.37(0.028)$ & $0.008(0.003)$ & $0.015(0.003)$ & $0.013(0.003)$ & $0.015(0.003)$ \\
\hline & 2 & $-0.48(0.043)$ & $-0.67(0.029)$ & $-0.52(0.027)$ & $-0.47(0.035)$ & $0.007(0.002)$ & $0.012(0.002)$ & $0.011(0.002)$ & $0.009(0.002)$ \\
\hline & 3 & $-0.81(0.065)$ & $-0.77(0.049)$ & $-0.66(0.048)$ & $-0.69(0.051)$ & $0.018(0.003)$ & $0.023(0.003)$ & $0.021(0.003)$ & $0.020(0.003)$ \\
\hline \multirow[t]{3}{*}{$\mathrm{M} \leftarrow$ SCS (het) } & 1 & $-0.29(0.029)$ & $-0.37(0.016)$ & $-0.27(0.014)$ & $-0.27(0.022)$ & & & & \\
\hline & 2 & $-0.35(0.039)$ & $-0.55(0.022)$ & $-0.40(0.019)$ & $-0.35(0.029)$ & & & & \\
\hline & 3 & $-0.54(0.047)$ & $-0.51(0.028)$ & $-0.41(0.025)$ & $-0.45(0.036)$ & & & & \\
\hline \multirow{3}{*}{$\mathrm{M} \rightarrow \mathrm{SCS}$ (het) } & 1 & & & & & $-0.054(0.002)$ & $-0.049(0.002)$ & $-0.050(0.002)$ & $-0.049(0.002)$ \\
\hline & 2 & & & & & $-0.052(0.002)$ & $-0.050(0.002)$ & $-0.051(0.002)$ & $-0.053(0.002)$ \\
\hline & 3 & & & & & $-0.044(0.002)$ & $-0.041(0.002)$ & $-0.044(0.002)$ & $-0.045(0.003)$ \\
\hline
\end{tabular}

${ }^{1} 1=5$ to 45 DIM; $2=46$ to 115 DIM; $3=116$ to 265 DIM; $4=266$ to 305 DIM.

$\stackrel{\complement}{2} \mathrm{M} \leftrightarrow \mathrm{SCS}=$ simultaneous model; $\mathrm{M} \leftarrow \mathrm{SCS}=$ model with recursive effect from SCS to milk; $\mathrm{M} \rightarrow \mathrm{SCS}=$ model with recursive effect from milk to SCS; M $\leftrightarrow$ SCS (het) $=$ het-

erogeneous simultaneous model; $\mathrm{M} \leftarrow$ SCS (het) = model with heterogeneous recursive effect from SCS to milk; M $\rightarrow$ SCS (het) $=$ model with heterogeneous recursive effect from milk to SCS. 
Table 3. Significance of differences based on a $99 \%\left(^{* *}\right)$ or $95 \%\left(^{*}\right)$ posterior credible interval between structural coefficients $(\lambda)$ for the same DIM interval ${ }^{1}$ across lactations, by model

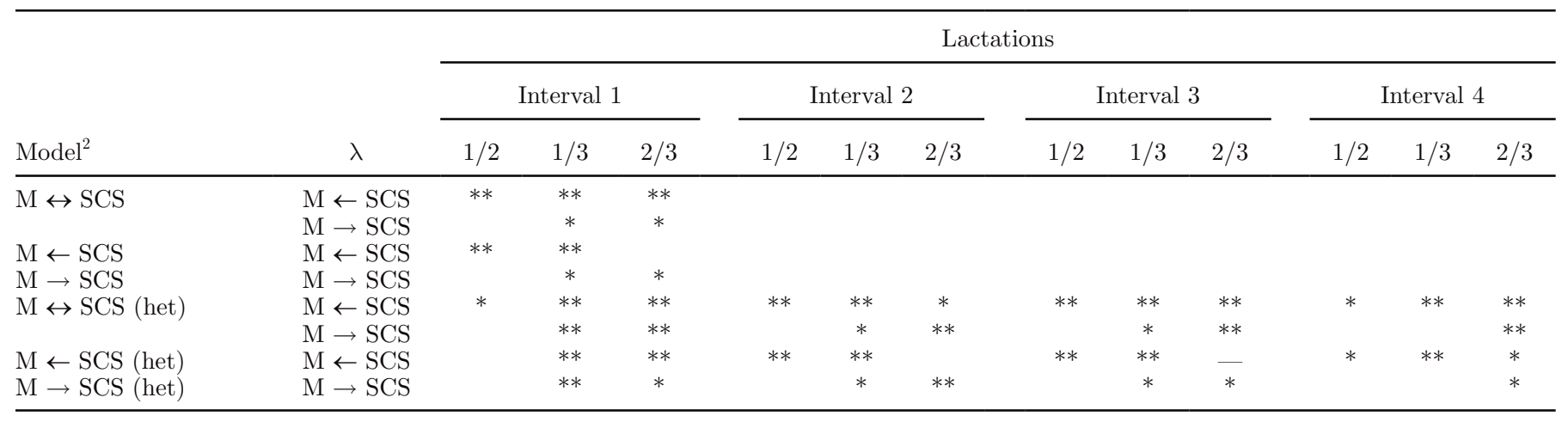

${ }^{1} 1=5$ to 45 DIM; $2=46$ to 115 DIM; $3=116$ to 265 DIM; $4=266$ to 305 DIM.

${ }^{2} \mathrm{M} \leftrightarrow \mathrm{SCS}=$ simultaneous model; $\mathrm{M} \leftarrow \mathrm{SCS}=$ model with recursive effect from SCS to milk; $\mathrm{M} \rightarrow \mathrm{SCS}=$ model with recursive effect from milk to SCS; $\mathrm{M} \leftrightarrow$ SCS (het) = heterogeneous simultaneous model; $\mathrm{M} \leftarrow$ SCS (het) = model with heterogeneous recursive effect from SCS to milk; $\mathrm{M} \rightarrow \mathrm{SCS}$ (het) = model with heterogeneous recursive effect from milk to SCS.

$$
\begin{aligned}
\mathrm{y}_{\mathrm{ijkM}} & =\left(\lambda_{\mathrm{M} \leftarrow \mathrm{SCS}}^{(\mathrm{k})} \times \mathrm{y}_{\mathrm{ijkSCS}}\right)+\mathbf{x}_{\mathrm{ijkM}}^{\prime} \mathbf{b}_{\mathrm{ijkM}} \\
& +\mathbf{z}_{\mathrm{ijkM}}^{\prime} \mathbf{a}_{\mathrm{i}}+\mathbf{z}_{\mathrm{ijkM}}^{\prime} \mathbf{p e}_{\mathrm{i}}+\mathrm{e}_{\mathrm{ijkM}},
\end{aligned}
$$

and

$$
\begin{gathered}
\mathrm{y}_{\mathrm{ijkSCS}}=\left(\lambda_{\mathrm{M} \rightarrow \mathrm{SCS}}^{(\mathrm{k})} \times \mathrm{y}_{\mathrm{ijkM}}\right)+\mathbf{x}_{\mathrm{ijkSCS}}^{\prime} \mathbf{b}_{\mathrm{ijkSCS}} \\
+\mathbf{z}_{\mathrm{ijkSCS}}^{\prime} \mathbf{a}_{\mathrm{i}}+\mathbf{z}_{\mathrm{ijkSCS}}^{\prime} \mathbf{p e}_{\mathrm{i}}+\mathrm{e}_{\mathrm{ijkSCS}},
\end{gathered}
$$

where $y_{\mathrm{ijkM}}$ and $\mathrm{y}_{\mathrm{ijkSCS}}$ are observed phenotypes for milk yield and SCS, respectively; $\lambda_{\mathrm{M} \leftarrow \mathrm{SCS}}^{(\mathrm{k})}$ and $\lambda_{\mathrm{M} \rightarrow \mathrm{SCS}}^{(\mathrm{k})}$ are structural parameters (the effect of change caused by the phenotype of the other trait) for lactation $k$; $\mathbf{x}_{\mathrm{ijkM}}$ and $\mathbf{x}_{\mathrm{ijkSCS}}$ are known incidence vectors for fixed effects; $\mathbf{b}_{\mathrm{ijkM}}$ and $\mathbf{b}_{\mathrm{ijkSCS}}$ are the vectors of fixed effects; $\mathbf{a}_{\mathrm{i}}$ and $\mathbf{p e}_{\mathrm{i}}$ are the vectors of random additive genetic and permanent environmental (PE) regression coefficients for cow i; $\mathbf{z}_{\mathrm{ijkM}}$ and $\mathbf{z}_{\mathrm{ijkSCS}}$ are vectors of covariates; and $\mathrm{e}_{\mathrm{ijkM}}$ and $\mathrm{e}_{\mathrm{ijkSCS}}$ are the residuals for milk and SCS, respectively. Fixed effects were the same for milk yield and
SCS, and they included an HTD effect and fixed regression within region-age at calving-season of calving classes. All regressions were functions of DIM and they were modeled with orthogonal Legendre polynomials of order 4. Heterogeneous residual covariances were allowed in 4 classes of DIM: 5 to 45, 46 to 115,116 to 265 , and 266 to 305. Residuals for observations taken at different DIM were assumed uncorrelated. Assume that elements of $\mathbf{a}_{\mathrm{i}}$ and $\mathbf{p} \mathbf{e}_{\mathrm{i}}$ are ordered as traits within regression coefficients, within lactations, and within animals, and let $\operatorname{var}\left(\mathbf{a}_{\mathrm{i}}\right)=\mathbf{G}, \operatorname{var}\left(\mathbf{p} \mathbf{e}_{\mathrm{i}}\right)=\mathbf{P}$, and $\operatorname{var}\left[\left(\mathrm{e}_{\mathrm{ijkM}}\right.\right.$, $\left.\left.\mathrm{e}_{\mathrm{ijkSCS}}\right)^{\prime}\right]=\mathbf{R}$ denote genetic, PE, and residual covariance matrices, respectively. This gives $\operatorname{var}(\mathbf{a})=\mathbf{A} \otimes$ $\mathbf{G}, \operatorname{var}(\mathbf{p e})=\mathbf{I} \otimes \mathbf{P}$, and $\operatorname{var}(\mathbf{e})=\mathbf{I} \otimes \mathbf{R}$, where $\mathbf{A}$ is an additive relationship matrix, $\mathbf{I}$ is an identity matrix, and $\otimes$ is the direct (Kronecker) product operator.

After rearrangement, the model equations become

\begin{tabular}{|c|c|c|c|c|c|c|c|c|c|c|c|c|c|c|c|c|c|c|c|}
\hline Model $^{2}$ & $\lambda$ & \multicolumn{18}{|c|}{ Interval } \\
\hline \multirow{2}{*}{$\overline{\mathrm{M} \leftrightarrow \mathrm{SCS}}$} & $\mathrm{M} \leftarrow \mathrm{SCS}$ & $* *$ & & & $* *$ & $* *$ & & $* *$ & & & $* *$ & $* *$ & $* *$ & & $* *$ & $* *$ & $* *$ & $* *$ & \\
\hline & $\mathrm{M} \rightarrow \mathrm{SCS}$ & $* *$ & $* *$ & $* *$ & $* *$ & & $*$ & $* *$ & $* *$ & & & $* *$ & $*$ & ** & & & ** & ** & \\
\hline $\mathrm{M} \leftarrow \mathrm{SCS}$ & $\mathrm{M} \leftarrow \mathrm{SCS}$ & $* *$ & & & $* *$ & $* *$ & & $* *$ & & & $* *$ & $* *$ & * & & $* *$ & & $* *$ & & \\
\hline
\end{tabular}

$$
\begin{aligned}
\mathrm{y}_{\mathrm{ijkM}} & -\left(\lambda_{\mathrm{M} \leftarrow \mathrm{SCS}}^{(\mathrm{k})} \times \mathrm{y}_{\mathrm{ijkSCS}}\right)=\mathbf{x}_{\mathrm{ijkM}}^{\prime} \mathbf{b}_{\mathrm{ijkM}} \\
+ & \mathbf{z}_{\mathrm{ijkM}}^{\prime} \mathbf{a}_{\mathrm{i}}+\mathbf{z}_{\mathrm{ijkM}}^{\prime} \mathbf{p e}_{\mathrm{i}}+\mathrm{e}_{\mathrm{ijkM}},
\end{aligned}
$$

Table 4. Significance of differences based on $99 \%(* *)$ or $95 \%(*)$ posterior credible interval between structural coefficients $(\lambda)$ for different DIM intervals ${ }^{1}$ within lactation for heterogeneous models

${ }^{1} 1=5$ to 45 DIM; $2=46$ to 115 DIM; $3=116$ to 265 DIM; $4=266$ to 305 DIM.

${ }^{2} \mathrm{M} \leftrightarrow \mathrm{SCS}=$ simultaneous model; $\mathrm{M} \leftarrow \mathrm{SCS}=$ model with recursive effect from SCS to milk; $\mathrm{M} \rightarrow \mathrm{SCS}=$ model with recursive effect from milk to SCS. 
Table 5. Posterior means of first-lactation residual covariances ${ }^{1}$ between milk and SCS in DIM intervals, by model

\begin{tabular}{|c|c|c|c|c|}
\hline DIM & Model $^{2}$ & $\sigma_{\mathrm{M}}^{2}$ & $\sigma_{\mathrm{M}-\mathrm{SCS}}$ & $\sigma_{\mathrm{SCS}}^{2}$ \\
\hline \multirow[t]{7}{*}{5 to 45} & M-SCS & $8.25(0.23)$ & $-0.41(0.06)$ & $1.06(0.03)$ \\
\hline & $\mathrm{M} \leftrightarrow \mathrm{SCS}$ & 8.14 & -0.32 & 1.09 \\
\hline & $\mathrm{M} \leftarrow \mathrm{SCS}$ & 8.19 & -0.32 & 1.07 \\
\hline & $\mathrm{M} \rightarrow \mathrm{SCS}$ & 8.26 & -0.42 & 1.07 \\
\hline & $\mathrm{M} \leftrightarrow \mathrm{SCS}$ (het) & 8.00 & -0.36 & 1.09 \\
\hline & $\mathrm{M} \leftarrow \mathrm{SCS}$ (het) & 7.98 & -0.31 & 1.07 \\
\hline & $\mathrm{M} \rightarrow \mathrm{SCS}$ (het) & 8.26 & -0.45 & 1.06 \\
\hline \multirow[t]{7}{*}{46 to 115} & M-SCS & $4.86(0.08)$ & $-0.25(0.02)$ & $0.88(0.01)$ \\
\hline & $\mathrm{M} \leftrightarrow \mathrm{SCS}$ & 4.88 & -0.28 & 0.89 \\
\hline & $\mathrm{M} \leftarrow \mathrm{SCS}$ & 4.87 & -0.26 & 0.88 \\
\hline & $\mathrm{M} \rightarrow \mathrm{SCS}$ & 4.86 & -0.25 & 0.88 \\
\hline & $\mathrm{M} \leftrightarrow \mathrm{SCS}$ (het) & 4.93 & -0.34 & 0.89 \\
\hline & $\mathrm{M} \leftarrow \mathrm{SCS}$ (het) & 4.90 & -0.33 & 0.88 \\
\hline & $\mathrm{M} \rightarrow \mathrm{SCS}$ (het) & 4.86 & -0.24 & 0.88 \\
\hline \multirow{7}{*}{116 to 265} & M-SCS & $4.08(0.04)$ & $-0.22(0.01)$ & $0.71(0.01)$ \\
\hline & $\mathrm{M} \leftrightarrow \mathrm{SCS}$ & 4.08 & -0.22 & 0.69 \\
\hline & $\mathrm{M} \leftarrow \mathrm{SCS}$ & 4.08 & -0.21 & 0.71 \\
\hline & $\mathrm{M} \rightarrow \mathrm{SCS}$ & 4.08 & -0.21 & 0.71 \\
\hline & $\mathrm{M} \leftrightarrow \mathrm{SCS}$ (het) & 4.08 & -0.20 & 0.69 \\
\hline & $\mathrm{M} \leftarrow \mathrm{SCS}$ (het) & 4.08 & -0.19 & 0.71 \\
\hline & $\mathrm{M} \rightarrow \mathrm{SCS}$ (het) & 4.08 & -0.21 & 0.71 \\
\hline \multirow[t]{7}{*}{266 to 305} & M-SCS & $3.88(0.14)$ & $-0.24(0.04)$ & $0.67(0.02)$ \\
\hline & $\mathrm{M} \leftrightarrow \mathrm{SCS}$ & 3.84 & -0.22 & 0.69 \\
\hline & $\mathrm{M} \leftarrow \mathrm{SCS}$ & 3.85 & -0.20 & 0.68 \\
\hline & $\mathrm{M} \rightarrow \mathrm{SCS}$ & 3.88 & -0.20 & 0.67 \\
\hline & $\mathrm{M} \leftrightarrow \mathrm{SCS}$ (het) & 3.83 & -0.20 & 0.69 \\
\hline & $\mathrm{M} \leftarrow \mathrm{SCS}$ (het) & 3.84 & -0.19 & 0.68 \\
\hline & $\mathrm{M} \rightarrow \mathrm{SCS}$ (het) & 3.87 & -0.19 & 0.67 \\
\hline
\end{tabular}

${ }^{1}$ Posterior SD for the M-SCS model estimates are in parentheses.

${ }^{2} \mathrm{M}-\mathrm{SCS}=$ standard multiple-trait model; $\mathrm{M} \leftrightarrow \mathrm{SCS}=$ simultaneous model; $\mathrm{M} \leftarrow \mathrm{SCS}=$ model with recursive effect from SCS to milk; $\mathrm{M} \rightarrow \mathrm{SCS}=$ model with recursive effect from milk to SCS; $\mathrm{M} \leftrightarrow$ SCS (het) $=$ heterogeneous simultaneous model; $\mathrm{M} \leftarrow$ SCS (het) = model with heterogeneous recursive effect from SCS to milk; $\mathrm{M} \rightarrow \mathrm{SCS}$ (het) = model with heterogeneous recursive effect from milk to SCS.

and

$$
\begin{gathered}
\mathrm{y}_{\mathrm{ijkSCS}}-\left(\lambda_{\mathrm{M} \rightarrow \mathrm{SCS}}^{(\mathrm{k})} \times \mathrm{y}_{\mathrm{ijkM}}\right)=\mathbf{x}_{\mathrm{ijkSCS}}^{\prime} \mathbf{b}_{\mathrm{ijkSCS}} \\
+\mathbf{z}_{\mathrm{ijkSCS}}^{\prime} \mathbf{a}_{\mathrm{i}}+\mathbf{z}_{\mathrm{ijkSCS}}^{\prime} \mathbf{p} \mathbf{e}_{\mathrm{i}}+\mathrm{e}_{\mathrm{ijkSCS}} .
\end{gathered}
$$

The system of equations can be written in matrix notation as

$$
\boldsymbol{\Lambda}^{(\kappa)} \mathbf{y}_{\mathrm{ijk}}=\mathbf{X}_{\mathrm{ijk}} \mathbf{b}+\mathbf{Z}_{\mathrm{ijk}} \mathbf{a}_{\mathrm{i}}+\mathbf{Z}_{\mathrm{ijk}} \mathbf{p} \mathbf{e}_{\mathrm{i}}+\mathbf{e}_{\mathrm{ijk}}
$$

where

$$
\boldsymbol{\Lambda}^{(\kappa)}=\left[\begin{array}{cc}
1 & -\lambda_{\mathrm{M} \leftarrow \mathrm{SCS}}^{(\mathrm{k})} \\
-\lambda_{\mathrm{M} \rightarrow \mathrm{SCS}}^{(\mathrm{k})} & 1
\end{array}\right] .
$$

Parameters of this model (b, a, pe, $\mathbf{G}, \mathbf{P}$, and $\mathbf{R})$ are called system parameters. When $\boldsymbol{\Lambda}^{(\kappa)}$ is a matrix of full rank, equation [1] can be rewritten as

$$
\begin{aligned}
& \mathbf{y}_{\mathrm{ijk}}=\boldsymbol{\Lambda}^{(\kappa)-1} \mathbf{X}_{\mathrm{ijk}} \mathbf{b}+\mathbf{Z}_{\mathrm{ijk}} \boldsymbol{\Lambda}^{(\kappa)-1} \mathbf{a}_{\mathrm{i}}+\mathbf{Z}_{\mathrm{ijk}} \boldsymbol{\Lambda}^{(\kappa)-1} \mathbf{p} \mathbf{e}_{\mathrm{i}} \\
& +\boldsymbol{\Lambda}^{(\kappa)-1} \mathbf{e}_{\mathrm{ijk}}=\mathbf{X}_{\mathrm{i}}{ }^{*} \mathbf{b}+\mathbf{Z}_{\mathrm{ijk}} \mathbf{a}_{\mathrm{i}}^{*}+\mathbf{Z}_{\mathrm{ijk}} \mathbf{p} \mathbf{e}_{\mathrm{i}}^{*}+\mathbf{e}_{\mathrm{ijk}}{ }^{*}
\end{aligned}
$$

with $\operatorname{var}\left(\mathbf{a}_{\mathrm{i}}{ }^{*}\right)=\mathbf{G}^{*}=\left(\mathbf{I} \otimes \mathbf{\Lambda}^{(\kappa)-1}\right) \mathbf{G}\left(\mathbf{I} \otimes \mathbf{\Lambda}^{(\kappa)-1}\right)^{\prime}$, $\operatorname{var}\left(\mathbf{p e}_{i}^{*}\right)=\mathbf{P}^{*}=\left(\mathbf{I} \otimes \boldsymbol{\Lambda}^{(\kappa)-1}\right) \mathbf{P}\left(\mathbf{I} \otimes \boldsymbol{\Lambda}^{(\kappa)-1}\right)^{\prime}, \quad$ and $\operatorname{var}\left(\mathbf{e}_{\mathrm{ijk}}{ }^{*}\right)=\mathbf{R}^{*}=\boldsymbol{\Lambda}^{(\kappa)-1} \mathbf{R} \boldsymbol{\Lambda}^{(\kappa)-1,}$, and $\mathbf{I}$ is an identity matrix of order equal to the number of regression coefficients times the number of lactations. Genetic parameters (i.e., heritabilities, genetic and phenotypic correlations) for traits can then be calculated in the usual manner from elements $\mathbf{G}^{*}, \mathbf{P}^{*}$, and $\mathbf{R}^{*}$. Similarly, breeding values for animal i $\left(\mathbf{a}_{i}{ }^{*}\right)$ can be derived from the system parameter $\left(\mathbf{a}_{\mathrm{i}}\right)$ as $\mathbf{a}_{\mathrm{i}}^{*}=\left(\mathbf{I} \otimes \mathbf{\Lambda}^{(\kappa)-1}\right) \mathbf{a}_{\mathrm{i}}$.

Seven specific models were fitted in this study and they can be described in simplified notation as follows: M-SCS is a standard multiple-trait model; $\mathbf{M} \leftrightarrow$ SCS is a simultaneous model (both $\lambda_{\mathrm{M} \leftarrow \mathrm{SCS}}^{(\mathrm{k})}$ and $\lambda_{\mathrm{M} \rightarrow \mathrm{SCS}}^{(\mathrm{k})}$ allowed to be different from zero); $\mathbf{M} \leftarrow \mathbf{S C S}$ is a model with a recursive effect from SCS to milk $\left(\lambda_{\mathrm{M} \rightarrow \mathrm{SCS}}^{(\mathrm{k})}=0\right)$; $\mathbf{M} \rightarrow \mathbf{S C S}$ is a model with a recursive effect from milk to $\operatorname{SCS}\left(\lambda_{\mathrm{M} \leftarrow \mathrm{SCS}}^{(\mathrm{k})}=0\right) ; \mathbf{M} \leftrightarrow \mathbf{S C S}$ (het) is a heterogeneous simultaneous model; $\mathbf{M} \leftarrow$ SCS (het) is a model with a heterogeneous recursive effect from SCS to milk; and $\mathbf{M} \rightarrow$ SCS (het) is a model with a heterogeneous recursive effect from milk to SCS. 
Table 6. Posterior means of genetic variance for the constant $\left(a_{0}\right)$ and linear terms $\left(a_{1}\right)$ of the lactation curve within 4 DIM intervals ${ }^{2}$ of the first-lactation milk yield, by model

\begin{tabular}{|c|c|c|c|c|c|c|c|c|}
\hline \multirow[b]{2}{*}{ Model $^{3}$} & \multicolumn{4}{|c|}{$\mathrm{a}_{0}$} & \multicolumn{4}{|c|}{$a_{1}$} \\
\hline & 1 & 2 & 3 & 4 & 1 & 2 & 3 & 4 \\
\hline M-SCS & \multirow{3}{*}{\multicolumn{4}{|c|}{$\begin{array}{l}5.95(0.40) \\
5.96 \\
5.96\end{array}$}} & \multicolumn{4}{|c|}{$1.17(0.08)$} \\
\hline $\mathrm{M} \leftrightarrow \mathrm{SCS}$ & & & & & & & & \\
\hline $\mathrm{M} \leftarrow \mathrm{SCS}$ & & & & & & & & \\
\hline $\mathrm{M} \rightarrow \mathrm{SCS}$ & \multicolumn{4}{|c|}{6.02} & \multicolumn{4}{|c|}{1.19} \\
\hline $\mathrm{M} \leftrightarrow \mathrm{SCS}$ (het) & 5.99 & 5.93 & 5.98 & 5.97 & 1.17 & 1.17 & 1.16 & 1.16 \\
\hline $\mathrm{M} \leftarrow \mathrm{SCS}$ (het) & 5.97 & 5.94 & 5.98 & 5.98 & 1.18 & 1.18 & 1.18 & 1.18 \\
\hline $\mathrm{M} \rightarrow \mathrm{SCS}$ (het) & 6.03 & 6.03 & 6.03 & 6.03 & 1.18 & 1.18 & 1.18 & 1.18 \\
\hline
\end{tabular}

${ }^{1}$ Posterior SD for the M-SCS model estimates are in parentheses.

${ }^{2} 1=5$ to 45 DIM; $2=46$ to 115 DIM; $3=116$ to 265 DIM; $4=266$ to 305 DIM.

${ }^{3} \mathrm{M}-\mathrm{SCS}=$ standard multiple-trait model; $\mathrm{M} \leftrightarrow \mathrm{SCS}=$ simultaneous model; $\mathrm{M} \leftarrow \mathrm{SCS}=$ model with recursive effect from SCS to milk; $\mathrm{M} \rightarrow \mathrm{SCS}=$ model with recursive effect from milk to SCS; $\mathrm{M} \leftrightarrow$ SCS (het) = heterogeneous simultaneous model; $\mathrm{M} \leftarrow$ SCS (het) = model with heterogeneous recursive effect from SCS to milk; $\mathrm{M} \rightarrow \mathrm{SCS}$ (het) = model with heterogeneous recursive effect from milk to SCS.

For heterogeneous models, different possible values of both $\lambda_{\mathrm{M} \leftarrow \mathrm{SCS}}^{(\mathrm{k})}$ and $\lambda_{\mathrm{M} \rightarrow \mathrm{SCS}}^{(\mathrm{k})}$ were postulated in 4 DIM intervals within each lactation: 5 to 45,46 to 115,116 to 265, and 266 to 305 DIM (the same as used for the definition of heterogeneous residual covariances). Models $\mathrm{M} \leftrightarrow \mathrm{SCS}, \mathrm{M} \leftarrow \mathrm{SCS}$, and $\mathrm{M} \rightarrow \mathrm{SCS}$ are, in fact, also heterogeneous with respect to structural coefficients (i.e., different values are allowed for different lactations). Heterogeneous matrices of structural coefficients generate heterogeneous covariance matrices $\left(\mathbf{G}^{*}, \mathbf{P}^{*}\right.$, and $\left.\mathbf{R}^{*}\right)$ and heterogeneous location parameters of the model. This means that there will be 3 sets of covariance matrices and genetic regression coefficients for models $\mathrm{M} \leftrightarrow \mathrm{SCS}, \mathrm{M} \leftarrow \mathrm{SCS}$, and $\mathrm{M} \rightarrow \mathrm{SCS}$, depending on lactation. The number of location and dispersion parameters for heterogeneous models will increase to 12; then the covariances and regression coef- ficients will depend on the lactation and the DIM in the lactation.

\section{METHODS}

All models were fitted using Markov chain Monte Carlo methods, and the algorithms for fitting SEqM followed the procedures of Gianola and Sorensen (2004) and $\mathrm{Wu}$ et al. (2007a). Bayesian assumptions included proper prior distributions for all model parameters: normal distributions for all location parameters, and inverted Wishart distributions for covariance components. Prior distributions for structural coefficients were independent normal, with a mean of zero and variance equal to 10,000. To achieve identification of parameters in the SEqM models, several restrictions had to be imposed on system parameters of these models. In the simultaneous models, residual covariances were set

Table 7. Posterior means of genetic variance ${ }^{1}$ for the constant $\left(\mathrm{a}_{0}\right)$ and linear terms $\left(\mathrm{a}_{1}\right)$ of lactation curve within 4 DIM intervals ${ }^{2}$ for the first-lactation SCS, by model

\begin{tabular}{|c|c|c|c|c|c|c|c|c|}
\hline \multirow[b]{2}{*}{ Model $^{3}$} & \multicolumn{4}{|c|}{$a_{0}$} & \multicolumn{4}{|c|}{$a_{1}$} \\
\hline & 1 & 2 & 3 & 4 & 1 & 2 & 3 & 4 \\
\hline M-SCS & \multicolumn{4}{|c|}{$0.36(0.03)$} & \multicolumn{4}{|c|}{$0.05(0.02)$} \\
\hline $\mathrm{M} \leftrightarrow \mathrm{SCS}$ & \multicolumn{4}{|c|}{0.37} & \multicolumn{4}{|c|}{0.05} \\
\hline $\mathrm{M} \leftarrow \mathrm{SCS}$ & \multirow{2}{*}{\multicolumn{4}{|c|}{$\begin{array}{l}0.37 \\
0.37\end{array}$}} & & & & \\
\hline $\mathrm{M} \rightarrow \mathrm{SCS}$ & & & & & & & & \\
\hline $\mathrm{M} \leftrightarrow \mathrm{SCS}$ (het) & 0.36 & 0.36 & 0.36 & 0.36 & 0.05 & 0.04 & 0.05 & 0.05 \\
\hline $\mathrm{M} \leftarrow \mathrm{SCS}$ (het) & 0.37 & 0.37 & 0.37 & 0.37 & 0.05 & 0.05 & 0.05 & 0.05 \\
\hline $\mathrm{M} \rightarrow$ SCS (het) & 0.36 & 0.37 & 0.36 & 0.37 & 0.05 & 0.05 & 0.05 & 0.05 \\
\hline
\end{tabular}

${ }^{1}$ Posterior SD for the M-SCS model estimates are in parentheses.

${ }^{2} 1=5$ to 45 DIM, $2=46$ to 115 DIM, $3=116$ to 265 DIM, $4=266$ to 305 DIM.

${ }^{3} \mathrm{M}-\mathrm{SCS}=$ standard multiple-trait model; $\mathrm{M} \leftrightarrow \mathrm{SCS}=$ simultaneous model; $\mathrm{M} \leftarrow \mathrm{SCS}=$ model with recursive effect from SCS to milk; $\mathrm{M} \rightarrow$ SCS $=$ model with recursive effect from milk to SCS; $\mathrm{M} \leftrightarrow$ SCS (het) = heterogeneous simultaneous model; $\mathrm{M} \leftarrow$ SCS (het) = model with heterogeneous recursive effect from SCS to milk; $\mathrm{M} \rightarrow \mathrm{SCS}$ (het) = model with heterogeneous recursive effect from milk to SCS. 
Table 8. Posterior means of permanent environmental variance ${ }^{1}$ for the constant $\left(\mathrm{pe}_{0}\right)$ and linear terms $\left(\mathrm{pe}_{1}\right)$ of lactation curve within 4 DIM intervals ${ }^{2}$ for the first-lactation milk yield, by model

\begin{tabular}{|c|c|c|c|c|c|c|c|c|}
\hline \multirow[b]{2}{*}{ Model $^{3}$} & \multicolumn{4}{|c|}{$\mathrm{pe}_{0}$} & \multicolumn{4}{|c|}{$\mathrm{pe}_{1}$} \\
\hline & 1 & 2 & 3 & 4 & 1 & 2 & 3 & 4 \\
\hline M-SCS & \multicolumn{4}{|c|}{$7.14(0.30)$} & \multicolumn{4}{|c|}{$0.99(0.06)$} \\
\hline $\mathrm{M} \leftrightarrow \mathrm{SCS}$ & \multicolumn{4}{|c|}{7.06} & \multirow{2}{*}{\multicolumn{4}{|c|}{$\begin{array}{l}0.98 \\
0.99\end{array}$}} \\
\hline $\mathrm{M} \leftarrow \mathrm{SCS}$ & \multirow{2}{*}{\multicolumn{4}{|c|}{$\begin{array}{l}7.15 \\
7.10\end{array}$}} & \multirow{2}{*}{\multicolumn{4}{|c|}{$\begin{array}{l}0.99 \\
0.98\end{array}$}} \\
\hline $\mathrm{M} \rightarrow \mathrm{SCS}$ & & & & & & & & \\
\hline $\mathrm{M} \leftrightarrow \mathrm{SCS}$ (het) & 7.08 & 7.09 & 7.04 & 7.03 & 0.99 & 1.00 & 0.99 & 0.99 \\
\hline $\mathrm{M} \leftarrow \mathrm{SCS}$ (het) & 7.13 & 7.18 & 7.11 & 7.12 & 1.01 & 1.03 & 1.01 & 1.01 \\
\hline $\mathrm{M} \rightarrow \mathrm{SCS}$ (het) & 7.08 & 7.08 & 7.08 & 7.08 & 0.99 & 0.99 & 0.99 & 0.99 \\
\hline
\end{tabular}

${ }^{1}$ Posterior SD for the M-SCS model estimates are in parentheses.

${ }^{2} 1=5$ to 45 DIM; $2=46$ to 115 DIM; $3=116$ to 265 DIM; $4=266$ to 305 DIM.

${ }^{3} \mathrm{M}-\mathrm{SCS}=$ standard multiple-trait model; $\mathrm{M} \leftrightarrow \mathrm{SCS}=$ simultaneous model; $\mathrm{M} \leftarrow \mathrm{SCS}=$ model with recursive effect from SCS to milk; $\mathrm{M} \rightarrow \mathrm{SCS}=$ model with recursive effect from milk to SCS; $\mathrm{M} \leftrightarrow$ SCS (het) = heterogeneous simultaneous model; $\mathrm{M} \leftarrow$ SCS (het) = model with heterogeneous recursive effect from SCS to milk; $\mathrm{M} \rightarrow \mathrm{SCS}$ (het) = model with heterogeneous recursive effect from milk to SCS.

to zero, and residual variances for SCS were assumed constant. In addition, the effects of fixed regressions for milk yield and HTD effects for SCS were removed from the respective models. Data for these models were precorrected for the effects that were removed from the model by using estimates of fixed regression coefficients for milk and the HTD effect for SCS from the multipletrait model (M-SCS). Restrictions for recursive models required setting to zero all residual covariances between milk and SCS.

Sampling schemes involved sampling from respective conditional distributions for location parameters (multivariate-normal for fixed and random effects of the model) and covariance components (inverted Wishart) and a Metropolis-Hasting step with normal proposal distribution for sampling the structural coefficient parameters $(\lambda)$. Conditional distributions for structural coefficients for recursive models were normal; thus, sampling of these parameters followed a regular Gibbs sampling scheme. Custom-written software was used for computations. A total of 120,000 samples were generated for each model, and 100,000 samples (after a burn-in period of 20,000 iterations) were used to estimate posterior means and standard deviations for model parameters. Convergence of Gibbs chains was examined by visual inspection of trace plots for selected parameters.

Models were compared by Bayes factors (BF) as defined in Kass and Raftery (1995). Suppose, for simplicity, that 2 models $\left(\mathrm{M}_{0}\right.$ and $\left.\mathrm{M}_{1}\right)$ are compared. Let the parameters for the model $\mathrm{M}_{\mathrm{k}}$ be $\boldsymbol{\theta}_{\mathrm{k}}$. The BF to contrast model $\mathrm{M}_{0}$ with model $\mathrm{M}_{1}$ is then $\mathrm{B}_{01}=\mathrm{p}(\mathbf{y} \mid \mathrm{M}$ $\left.=\mathrm{M}_{0}\right) / \mathrm{p}\left(\mathbf{y} \mid \mathrm{M}=\mathrm{M}_{1}\right)$, where $\mathrm{p}\left(\mathbf{y} \mid \mathrm{M}=\mathrm{M}_{\mathrm{k}}\right)=\int \mathrm{p}\left(\mathbf{y} \mid \boldsymbol{\theta}_{\mathrm{k}}\right.$, $\left.\mathrm{M}=\mathrm{M}_{\mathrm{k}}\right) \mathrm{p}\left(\boldsymbol{\theta}_{\mathrm{k}} \mid \mathrm{M}=\mathrm{M}_{\mathrm{k}}\right) \mathrm{d} \boldsymbol{\theta}_{\mathrm{k}}$ is an integrated (marginal) likelihood, and $\mathrm{p}\left(\boldsymbol{\theta}_{\mathrm{k}} \mid \mathrm{M}=\mathrm{M}_{\mathrm{k}}\right)$ is the prior density under model k. If the prior probabilities of each model being true are equal, then the $\mathrm{BF}$ gives the ratio between the posterior probabilities of each pair of models. Bayes factor values greater than 150 (or a $\log$ of $\mathrm{B}_{01}$ greater than 10) indicates very strong evidence in favor of model $\mathrm{M}_{0}$. The posterior probability of a given model can be calculated easily using marginal likelihoods of competing models. The marginal density $\mathrm{p}\left(\mathbf{y} \mid \mathrm{M}=\mathrm{M}_{\mathrm{k}}\right)$ was estimated by the harmonic mean of the likelihood values from the Gibbs chain as

$$
\mathrm{p}\left(\mathbf{y} \mid \mathrm{M}=\mathrm{M}_{\mathrm{k}}\right)=\left\{1 / \mathrm{m} \Sigma\left[\mathrm{p}\left(\mathbf{y} \mid \theta_{\mathrm{k}}^{\mathrm{i}}, \mathrm{M}_{\mathrm{k}}\right)\right]^{-1}\right\}^{-1},
$$

where $\theta_{\mathrm{k}}^{\mathrm{i}}(\mathrm{i}=1,2, \ldots, \mathrm{m})$ are draws obtained from the posterior distribution under model $\mathrm{k}$.

Population covariance components and selected genetic parameters (heritabilities, genetic and environmental correlations for the first 2 regression coefficients and on a daily basis) were derived from the estimates of system covariances. The first regression coefficient determines the overall level of the lactation curve and is equivalent to the cumulative yield over the lactation, whereas the second coefficient can serve as a measure of lactation persistency (Jamrozik et al., 2002). Estimated breeding values of bulls with at least 20 daughters (265 sires) and cows with TD records (10,832 cows) were calculated for each lactation for the 305-d milk yield, average daily SCS, and persistency of lactation by using posterior samples of genetic regression coefficients. Following the CTDM, persistency of lactation for genetic evaluation purposes was defined as a difference in milk yield between d 280 and 60 of lactation. Combined EBV were then derived as averages of within-lactation 
Table 9. Posterior means of permanent environmental variance ${ }^{1}$ for the constant $\left(\mathrm{pe}_{0}\right)$ and linear terms $\left(\mathrm{pe}_{1}\right)$ of the lactation curve within 4 DIM intervals ${ }^{2}$ for first-lactation SCS, by model

\begin{tabular}{|c|c|c|c|c|c|c|c|c|}
\hline \multirow[b]{2}{*}{ Model $^{3}$} & \multicolumn{4}{|c|}{$\mathrm{pe}_{0}$} & \multicolumn{4}{|c|}{$\mathrm{pe}_{1}$} \\
\hline & 1 & 2 & 3 & 4 & 1 & 2 & 3 & 4 \\
\hline M-SCS & \multicolumn{4}{|c|}{$0.98(0.03)$} & \multicolumn{4}{|c|}{$0.15(0.02)$} \\
\hline $\mathrm{M} \leftrightarrow \mathrm{SCS}$ & \multicolumn{4}{|c|}{0.91} & \multicolumn{4}{|c|}{0.13} \\
\hline $\mathrm{M} \leftarrow \mathrm{SCS}$ & \multirow{2}{*}{\multicolumn{4}{|c|}{$\begin{array}{l}0.97 \\
0.98\end{array}$}} & \multirow{2}{*}{\multicolumn{4}{|c|}{$\begin{array}{l}0.15 \\
0.15\end{array}$}} \\
\hline $\mathrm{M} \rightarrow \mathrm{SCS}$ & & & & & & & & \\
\hline $\mathrm{M} \leftrightarrow \mathrm{SCS}$ (het) & 0.91 & 0.90 & 0.91 & 0.91 & 0.13 & 0.13 & 0.13 & 0.13 \\
\hline $\mathrm{M} \leftarrow \mathrm{SCS}$ (het) & 0.98 & 0.98 & 0.98 & 0.98 & 0.15 & 0.15 & 0.15 & 0.15 \\
\hline $\mathrm{M} \rightarrow \mathrm{SCS}$ (het) & 0.98 & 0.98 & 0.98 & 0.98 & 0.15 & 0.15 & 0.15 & 0.15 \\
\hline
\end{tabular}

${ }^{1}$ Posterior SD for the M-SCS model estimates are in parentheses.

${ }^{2} 1=5$ to 45 DIM; $2=46$ to 115 DIM; $3=116$ to 265 DIM; $4=266$ to 305 DIM.

${ }^{3} \mathrm{M}-\mathrm{SCS}=$ standard multiple-trait model; $\mathrm{M} \leftrightarrow \mathrm{SCS}=$ simultaneous model; $\mathrm{M} \leftarrow \mathrm{SCS}=$ model with recursive effect from SCS to milk; $M \rightarrow$ SCS $=$ model with recursive effect from milk to SCS; $M \leftrightarrow$ SCS (het) = heterogeneous simultaneous model; $\mathrm{M} \leftarrow$ SCS (het) = model with heterogeneous recursive effect from SCS to milk; $\mathrm{M} \rightarrow \mathrm{SCS}$ (het) = model with heterogeneous recursive effect from milk to SCS.

EBV for those 3 traits. Estimated breeding values from different models were compared in terms of means, SD, and product-moment correlations.

\section{RESULTS}

\section{Model Comparison}

Model comparison criteria (Table 1) indicated the superiority of simultaneous models for milk yield and SCS over their competitors. The model with heterogeneous within-lactation structural coefficients was the most plausible specification; the standard multipletrait model outperformed both recursive models with a single structural effect per lactation. There was not very strong evidence for either recursive model when $\mathrm{M} \rightarrow \mathrm{SCS}$ and $\mathrm{M} \leftarrow$ SCS were contrasted in terms of $\mathrm{BF}$.

\section{Structural Coefficients}

Estimates of structural coefficients (Table 2) generally followed the trends reported in other studies. Simultaneous models indicated a negative effect of SCS on milk yield (infection effect) and a smaller positive effect of milk yield on SCS (stress effect). Slightly smaller direct effects of SCS on milk yield were estimated with the recursive models $\mathrm{M} \leftarrow \mathrm{SCS}$, and a negative effect of milk yield on SCS (dilution effect) was observed in M $\rightarrow$ SCS models. All structural coefficients for all models were significantly different from zero (the $99 \%$ credible interval did not include 0 ). The absolute values of all structural coefficients increased with lactation number. The pattern of changes for within-lactation structural coefficients from SCS to milk yield generally followed the shape of the lactation curve for SCS. Similarly, within-lactation structural coefficients from

Table 10. Range of estimates (all models) for heritability of the first 2 regression coefficients for milk yield and SCS, and genetic and permanent environmental correlations between milk yield and SCS, by lactation

\begin{tabular}{|c|c|c|c|c|c|c|}
\hline \multirow{2}{*}{ Parameter } & \multirow{2}{*}{ Trait } & \multirow{2}{*}{ Lactation } & \multicolumn{4}{|c|}{ Coefficient $^{1}$} \\
\hline & & & \multicolumn{2}{|c|}{$\mathrm{a}_{0}$} & \multicolumn{2}{|c|}{$a_{1}$} \\
\hline \multirow[t]{4}{*}{ Heritability } & Milk & 1 & 0.45 & 0.46 & 0.53 & 0.55 \\
\hline & & 2 & 0.43 & 0.44 & 0.50 & 0.50 \\
\hline & & 3 & 0.40 & 0.41 & 0.50 & 0.50 \\
\hline & & 3 & 0.30 & 0.31 & 0.37 & 0.40 \\
\hline \multirow[t]{3}{*}{ Genetic correlation } & & 1 & 0.11 & 0.15 & -0.19 & -0.13 \\
\hline & & 2 & -0.05 & -0.01 & -0.40 & -0.36 \\
\hline & & 3 & -0.04 & -0.01 & -0.46 & -0.41 \\
\hline \multirow[t]{3}{*}{ Permanent environmental correlation } & & 1 & -0.13 & -0.10 & -0.22 & -0.19 \\
\hline & & 2 & -0.26 & -0.22 & -0.42 & -0.39 \\
\hline & & 3 & -0.27 & -0.21 & -0.28 & -0.22 \\
\hline
\end{tabular}

${ }^{1}$ Constant $\left(\mathrm{a}_{0}\right)$ and linear terms $\left(\mathrm{a}_{1}\right)$ of the lactation curve. 


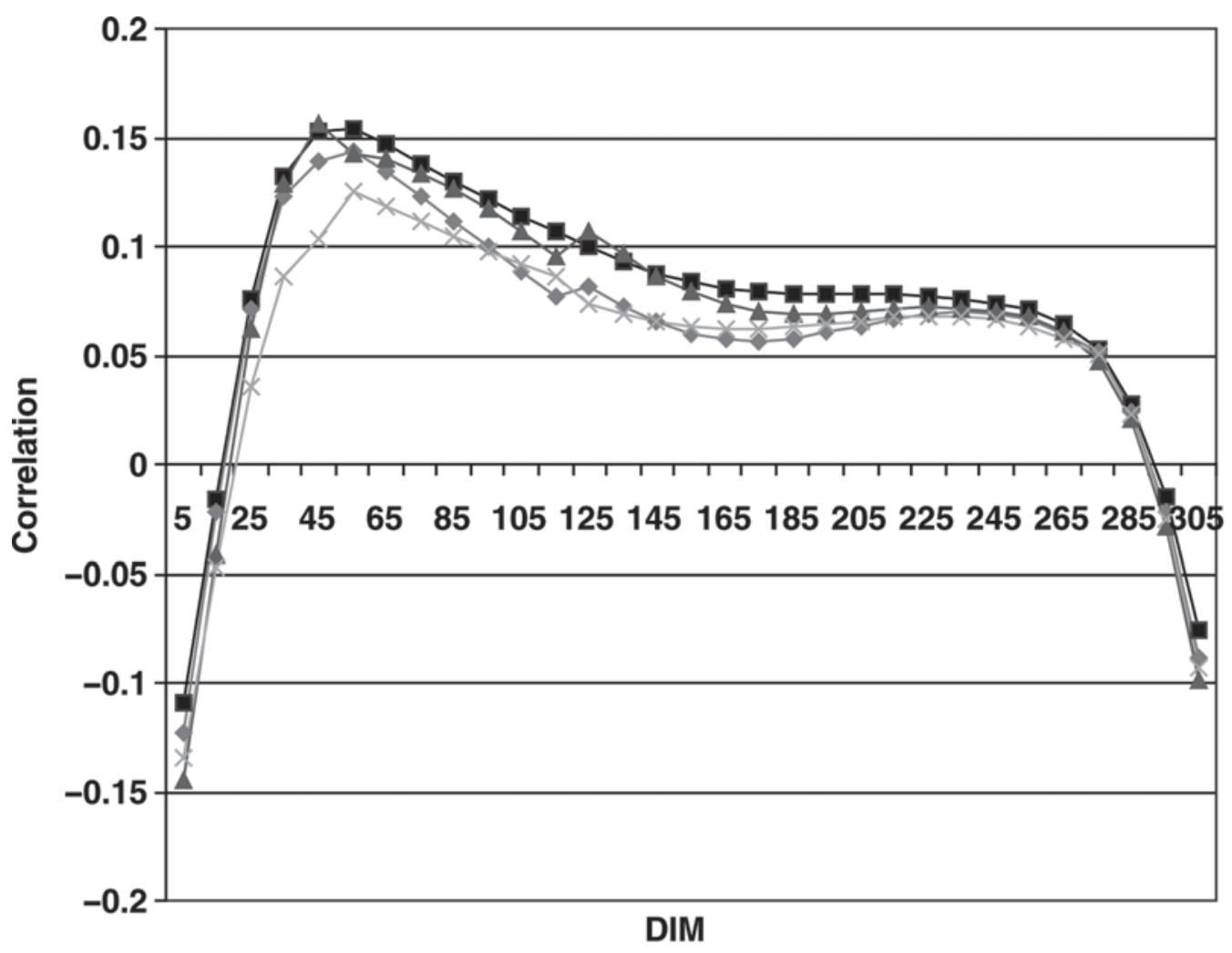

\section{$\rightarrow-$ M-SCS $\rightarrow-M<->S C S$ (het) $\rightarrow$ M<-SCS (het) $\rightarrow-$ M->SCS (het)}

Figure 3. Daily genetic correlations between first-lactation milk and SCS for the multiple-trait and heterogeneous models. M-SCS $=$ standard multiple-trait model; $\mathrm{M} \leftrightarrow$ SCS (het) = heterogeneous simultaneous model; $\mathrm{M} \leftarrow$ SCS (het) $=$ model with heterogeneous recursive effect from SCS to milk; $\mathrm{M} \rightarrow$ SCS (het) = model with heterogeneous recursive effect from milk to SCS.

milk to SCS resembled the general shape of changes for milk yield during lactation. Heterogeneity of structural coefficients was documented for the majority of both across- and within lactation comparisons (Tables 3 and 4 ), with no evident pattern in differences among respective coefficients.

\section{Covariance Components and Genetic Parameters}

Estimates of residual covariances (Table 5 for the first-lactation estimates) showed very small differences between models in all periods of lactation. Posterior SD of residual variances (and of other variances of regression coefficients discussed later) were calculated for the M-SCS model only, to give an overall measure of the variability of estimates. The SEqM covariances between milk and SCS were similar to estimates obtained from the multiple-trait model in spite of restrictions imposed on the respective system residual covariances. This indicated that structural relationships were sufficient to account for residual covariability between traits.
Genetic variance for the constant (overall level) and linear (persistency measure) terms of the lactation curve did not differ much between models (Tables 6 and 7 for first-lactation milk yield and SCS, respectively). A slight increase in estimates was observed for SEqM models compared with the M-SCS model. No apparent heterogeneity between DIM intervals was detected for these parameters. The same comments apply to estimates of PE variances (Tables 8 and 9). Estimates of variances (residual, genetic, and $\mathrm{PE}$ ) for lactations 2 and 3 generally showed similar patterns (results not shown).

Table 10 summarizes the differences among heritability, genetic correlations, and PE correlations for the first 2 regression coefficients among all models (including heterogeneous estimates according to lactation number and DIM in lactation). Heritabilities of the constant and linear regression coefficients of the firstlactation curves for milk and SCS indicated virtually no differences between models. Heritabilities for milk yield showed no heterogeneity in DIM intervals within 


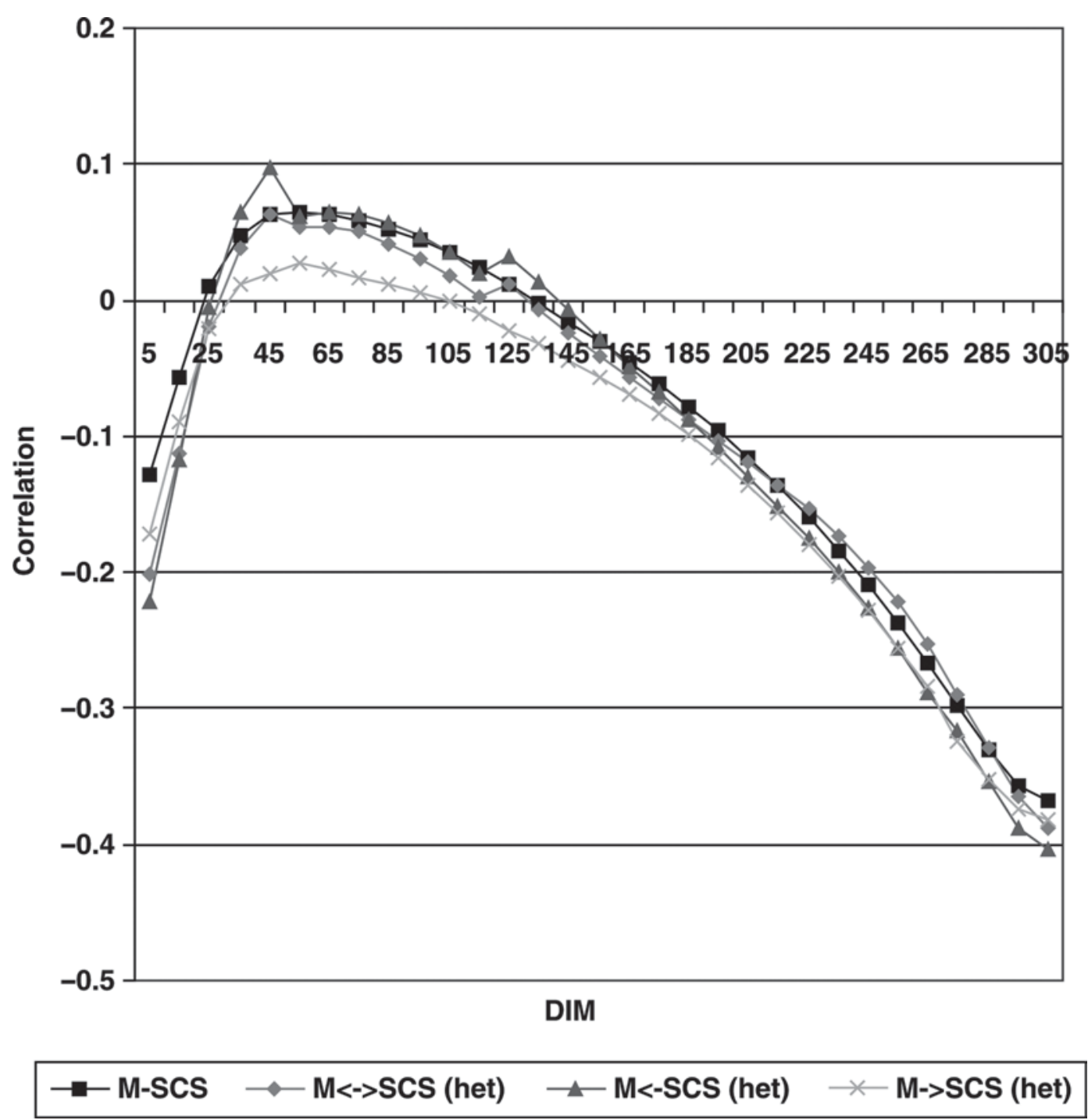

Figure 4. Daily genetic correlations between second-lactation milk and SCS for the multiple-trait and heterogeneous models. M-SCS $=$ standard multiple-trait model; $\mathrm{M} \leftrightarrow$ SCS (het) = heterogeneous simultaneous model; $\mathrm{M} \leftarrow$ SCS (het) = model with heterogeneous recursive effect from SCS to milk; $\mathrm{M} \rightarrow$ SCS (het) = model with heterogeneous recursive effect from milk to SCS.

lactations. Genetic and PE correlations between milk yield and SCS for the first 2 regression coefficients were similar between models, with slightly more heterogeneity of estimates between DIM intervals compared with the estimates of heritability.

Relatively larger differences among models were observed for estimates of daily genetic parameters. Genetic correlations between milk yield and SCS on the same DIM are plotted in Figures 3, 4, and 5 for the heterogeneous models and for lactations 1, 2, and 3 , respectively. The pattern of correlations was similar to those reported in other studies (i.e., Samore et al., 2008), from mostly positive values in the first lactation to all negative correlations in the third lactation. Estimates from the multiple-trait model were larger in absolute terms in the first lactation and smaller in the third lactation when compared with corresponding estimates from the SEqM. A paired $t$-test indicated significant differences $(P<0.001)$ between MT and all SEqM models. Estimates from $\mathrm{M} \leftrightarrow$ SCS (het) were significantly different from those of heterogeneous recursive models (with the exception of lactation 2); heterogeneous model estimates differed significantly in most cases (6 out of 9 comparisons) from their homogeneous (within-lactation) counterparts. Correlations in PE effects between milk yield and SCS on a daily basis followed a more or less similar pattern of differences among models as daily genetic correlations (results not shown). Phenotypic correlations between milk and SCS on the same DIM are shown in Figures 6, 7, and 8. All 


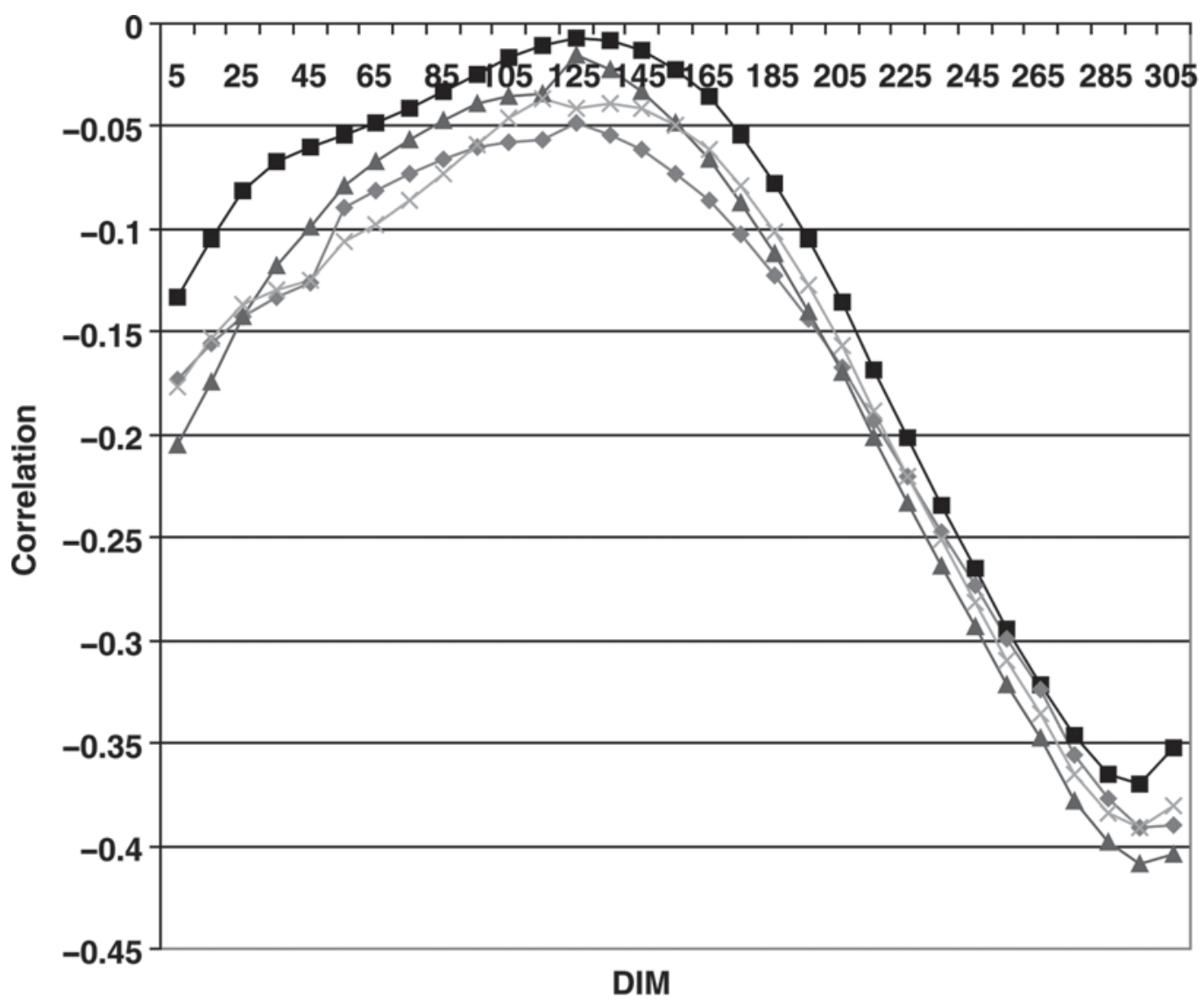

\section{$\rightarrow-$ M-SCS $\rightarrow$ M<->SCS (het) $\rightarrow$ M<-SCS (het) $\rightarrow$ M->SCS (het)}

Figure 5. Daily genetic correlations between third-lactation milk and SCS for the multiple-trait and heterogeneous models. M-SCS $=$ standard multiple-trait model; $\mathrm{M} \leftrightarrow$ SCS (het) = heterogeneous simultaneous model; $\mathrm{M} \leftarrow$ SCS (het) = model with heterogeneous recursive effect from SCS to milk; $\mathrm{M} \rightarrow$ SCS (het) = model with heterogeneous recursive effect from milk to SCS.

correlations for all lactations were negative; there was a slight decrease in estimates with lactation number. Although differences among models for these correlations were smaller than for corresponding daily genetic and PE parameters, SEqM estimates were significantly ( $P$ $<0.0001)$ different from the M-SCS model parameters, with the exception of model $\mathrm{M} \leftarrow$ SCS (het) for the first 2 lactations, and model $\mathrm{M} \leftarrow$ SCS for the third lactation.

Daily heritability curves (Figures 9 and 10 for the first lactation and for heterogeneous models only) showed similar shapes between models. Differences among SEqM models and the M-SCS models were significant $(P<0.0001)$ except for comparisons of M-SCS with M $\leftarrow$ SCS and M-SCS with M $\leftarrow$ SCS (het).

\section{$E B V$}

Correlations between EBV from different models for within lactation and combined 305-d milk yield, daily
SCS, and lactation persistency were all larger than 0.99 for both bulls and cows. This would indicate very little (if any) reranking of animals if SEqM were used for genetic evaluation compared with traditional multipletrait evaluation. Table 11 gives estimates of average EBV and their standard deviations for bulls and cows for combined traits. The variation in EBV was practically the same for all models. The SEqM gave, on average, higher EBV for milk yield compared with the M-SCS model; heterogeneous models showed the highest overall averages for this trait for both groups of animals. The opposite, however, could be observed for SCS. Combined lactation persistency showed more variation in means and $\mathrm{SD}$ among models.

\section{DISCUSSION}

Simultaneous and recursive models for the first 3 lactation TD data of milk and SCS were fitted in 


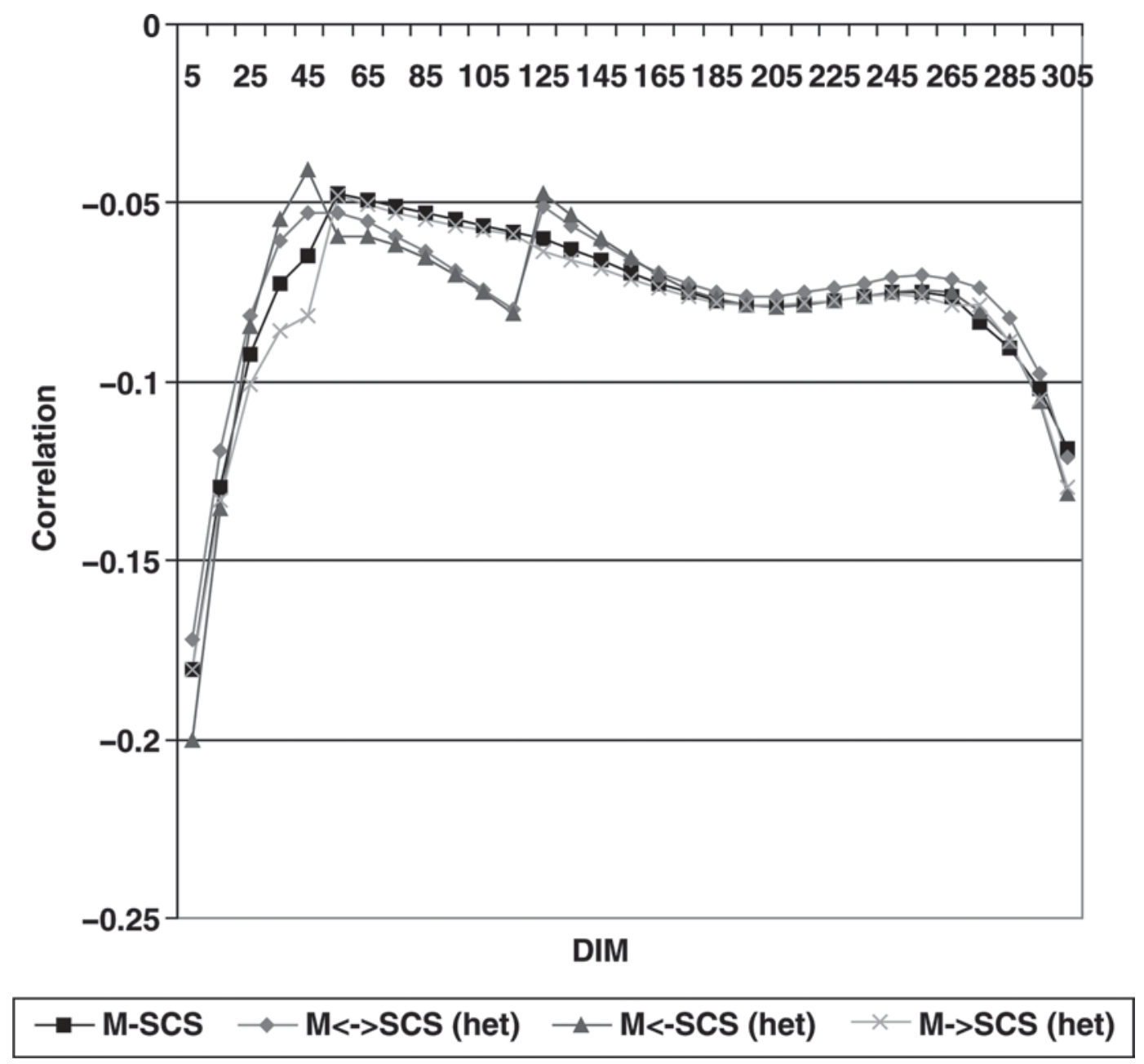

Figure 6. Daily phenotypic correlations between first-lactation milk and SCS for the multiple-trait and heterogeneous models. M-SCS $=$ standard multiple-trait model; $\mathrm{M} \leftrightarrow$ SCS (het) = heterogeneous simultaneous model; $\mathrm{M} \leftarrow$ SCS (het) = model with heterogeneous recursive effect from SCS to milk; $M \rightarrow$ SCS (het) = model with heterogeneous recursive effect from milk to SCS.

this study, accounting for the longitudinal nature of both traits through regressions on DIM with fixed and random coefficients. Overall results, in terms of model plausibility, confirmed the findings of Wu et al. (2007a). Phenotypic relationships between milk and SCS in all 3 lactations seem to be driven by a combination of 2 mechanisms. An infection effect caused a decrease in milk yield for cows with a higher SCS, and the stress effect resulted in an increase of SCS for higher producing cows. The results of de los Campos et al. (2006) favored the model with a negative recursive effect from SCS to milk yield. The absolute values of structural coefficient estimates obtained in this study were smaller than the results of other authors. Wu et al. (2007a) reported a decrease in milk yield of approximately $1.8 \mathrm{~kg}$ for every unit of SCS, and an increase of approximately 0.04 points for SCS for every kilogram of milk yield during the first $120 \mathrm{~d}$ of lactation. Estimates of the effect of
SCS on milk yield in our study, however, were in good agreement with phenotypic estimates of milk losses caused by SCS in Canadian Holstein cows (Dürr et al., 2008). They reported milk losses per unit increase from 0.33 to $0.55 \mathrm{~kg} / \mathrm{d}$ in the first lactation, and from 0.77 to $1.78 \mathrm{~kg} / \mathrm{d}$ in later lactations. Differences between our estimates and those by de los Campos et al. (2006) and Wu et al. (2007a) could be caused by not accounting for the health status of the cow (clinical mastitis) in the current research. Differences between populations (Canadian Holsteins vs. Norwegian Reds) might also have contributed.

Heterogeneity was found in the values of all structural coefficients across and within lactations. The intensity of structural relationships between milk yield and SCS increases with the age of the cow (consecutive lactations). This cannot be attributed only to the simple scale effect because both milk yield and SCS showed 


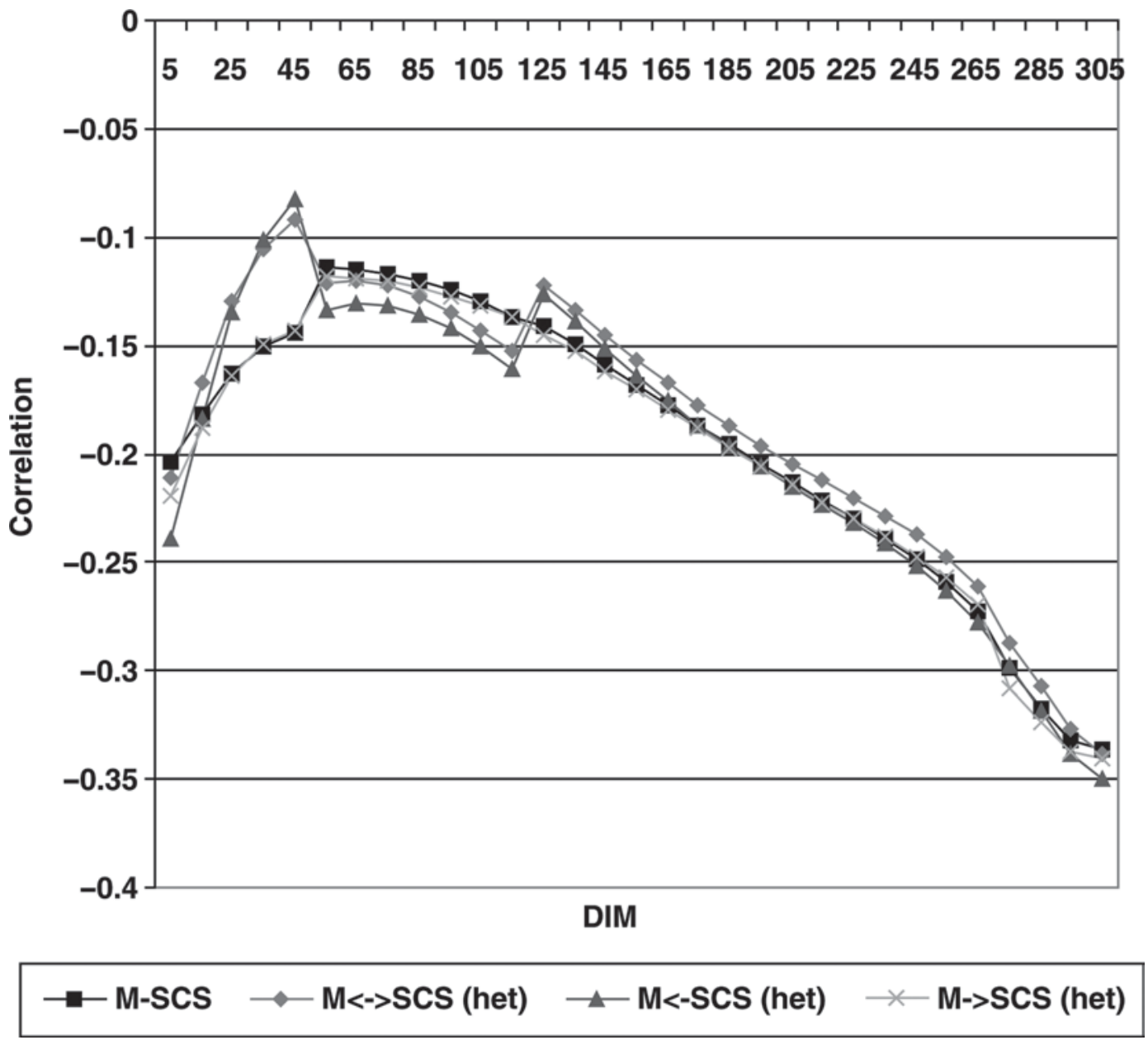

Figure 7. Daily phenotypic correlations between second-lactation milk and SCS for the multiple-trait and heterogeneous models. M-SCS $=$ standard multiple-trait model; $\mathrm{M} \leftrightarrow$ SCS (het) = heterogeneous simultaneous model; $\mathrm{M} \leftarrow$ SCS (het) = model with heterogeneous recursive effect from SCS to milk; $\mathrm{M} \rightarrow$ SCS (het) = model with heterogeneous recursive effect from milk to SCS.

an increasing trend with lactation number. Wu et al. (2007a) also reported larger estimates of direct effects for higher producing cows. The largest effect of either trait on the other occurred at DIM around the peak of lactation. Wu et al. (2007a) also reported larger values for direct effects in the first $60 \mathrm{~d}$ of lactation compared with the subsequent $60-\mathrm{d}$ period. Modeling the heterogeneity of within-lactation structural coefficients was attempted in our study by fitting them separately in 4 DIM intervals within each lactation. The selection of those intervals followed the pattern of changes in residual covariances for milk yield, as implemented in the original version of the CTDM (Schaeffer et al., 2000). Definitions of intervals could be different, but drastic changes in the pattern of structural coefficients for other scenarios are not expected.

Estimates of covariance components and genetic parameters for the first 2 regression coefficients for milk yield in the first lactation were similar to those obtained by Jamrozik et al. (2002). Daily covariance components and respective genetic parameters were in line with other estimates for Canadian Holsteins (Muir et al., 2004; Bohmanova et al., 2008). Modeling causal relationships between TD milk yield and SCS did not cause dramatic changes in estimated covariance components and the respective genetic parameters for regression coefficients. Larger effects, however, with statistically significant differences between models, were observed for variances, heritabilities, and correlations expressed on a daily basis. Results from other studies indicated changes in genetic (Wu et al., 2007a) and phenotypic (de los Campos et al., 2006) correlations between milk yield and SCS for simultaneous and recursive repeatability models when compared with multiple-trait estimates. The heterogeneity of structural parameters resulted in a heterogeneity of genetic parameters. This implied, in particular, that genetic $(\mathbf{G})$, and permanent environmental $(\mathbf{P})$ covariance matrices from the het- 


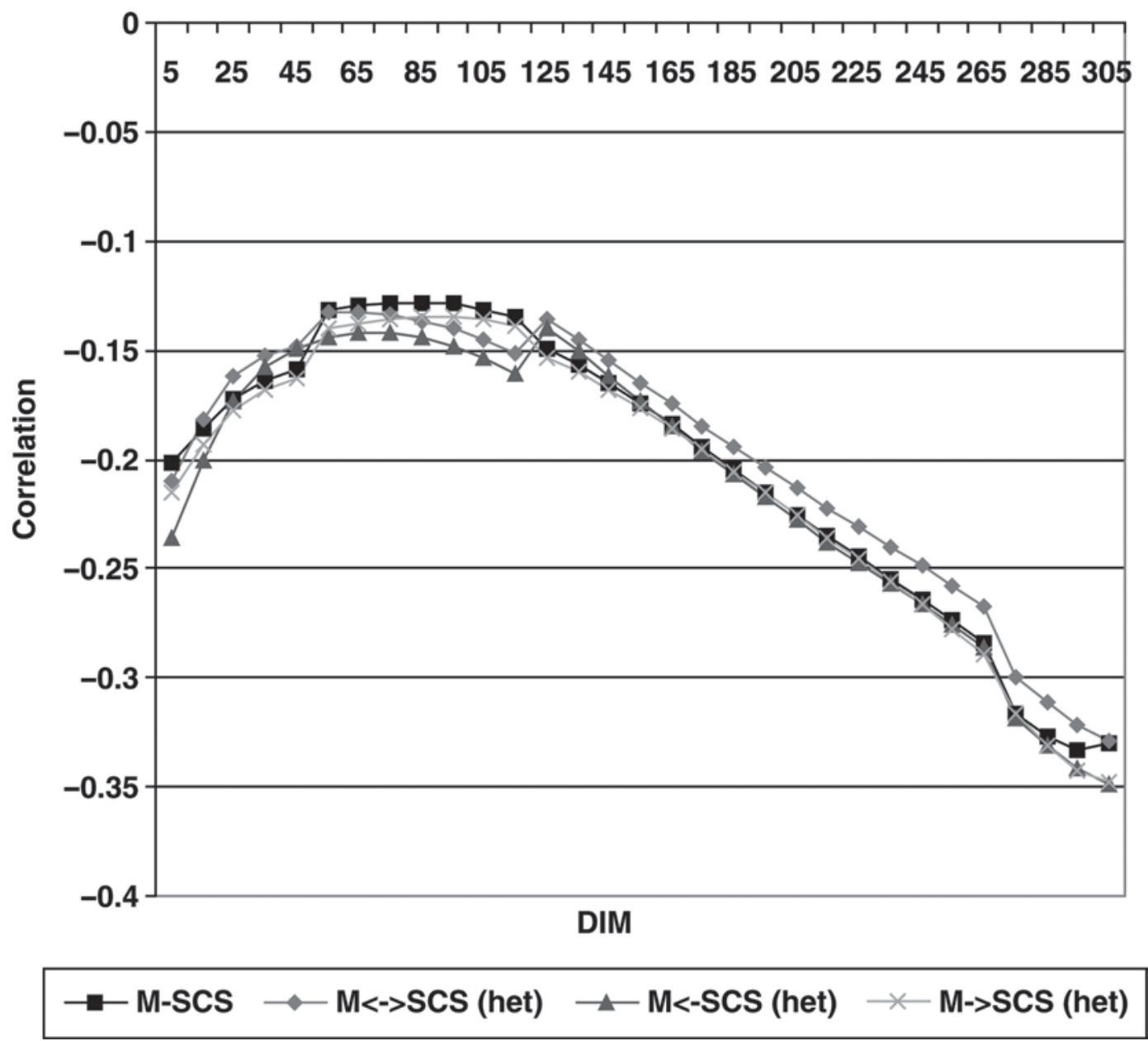

Figure 8. Daily phenotypic correlations between third-lactation milk and SCS for the multiple-trait and heterogeneous models. M-SCS $=$ standard multiple-trait model; $\mathrm{M} \leftrightarrow$ SCS (het) = heterogeneous simultaneous model; $\mathrm{M} \leftarrow$ SCS (het) = model with heterogeneous recursive effect from SCS to milk; M $\rightarrow$ SCS (het) = model with heterogeneous recursive effect from milk to SCS.

erogeneous models take different values (12 possibilities in our study), depending on the stage of lactation. This also applies to genetic parameters derived from those matrices. For example, heritability of the overall level of milk production (the first regression coefficient) is conditional on the lactation number as well as on DIM (4 possibilities) in lactation.

No changes in rankings of animals (both bulls and cows) for milk yield, SCS, and lactation persistency would be expected when causal relationships between milk yield and SCS on the same TD are accounted for in the evaluation model. No practical benefits would be achieved when using models with causal relationships between milk and SCS for genetic evaluation purposes. Variability of EBV from different models was not influenced by the specific parameterization. An average genetic level for selected groups of bulls and cows increased (decreased) for milk yield (SCS). This could indicate possible changes in estimates of genetic trends for these traits when compared with estimates from the standard models.

Simultaneous models required setting up exclusion restrictions to achieve model identification. This seems to be one of the drawbacks of this type of model. Records were precorrected for the effects that were removed from the model. An alternative could be to include additional (nonsignificant) effects in the original models for both milk yield and SCS. This would eliminate the identification problem, possibly without great consequences on inferences for the remaining parameters. Another possibility would be to use different fixed effects for milk and SCS. This would, however, require redesigning the CTDM with respect to fixed effects for those traits. To achieve identification at the level of likelihood, residual covariances were set to zero for all SEqM models. An interesting option would be to set restrictions on other covariances (PE and genetic) and to examine the possible impact of those param- 

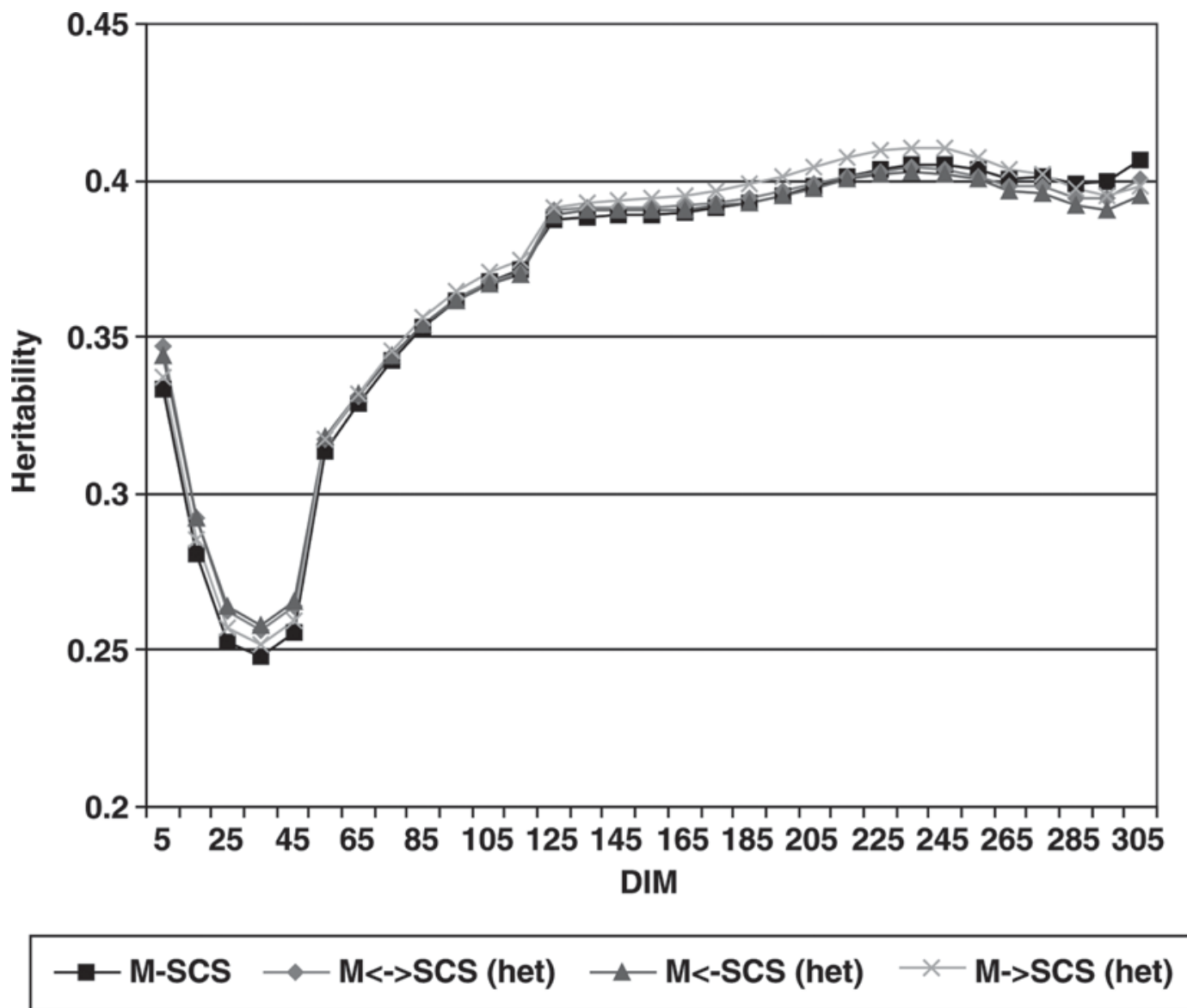

Figure 9. Daily heritability of first-lactation milk yield for the multiple-trait and heterogeneous models. M-SCS $=$ standard multiple-trait model; $\mathrm{M} \leftrightarrow \mathrm{SCS}$ (het) = heterogeneous simultaneous model; $\mathrm{M} \leftarrow$ SCS (het) = model with heterogeneous recursive effect from SCS to milk; $\mathrm{M} \rightarrow \mathrm{SCS}$ (het) $=$ model with heterogeneous recursive effect from milk to SCS.

eterizations. Those models would have a substantially smaller number of covariance components to estimate.

Heterogeneous recursive models applied in this study can be seen as a reparameterization of the standard (multiple-trait) model. All 3 models had exactly the same number of parameters. Formal model comparison methods (such as BF) do not give an answer regarding the plausibility of those models because they lead to the same likelihood after a suitable transformation. This was reflected in relatively similar values for estimates of the marginal likelihood for those models that, in fact, should yield the same values. The actual differences might be explained by Monte Carlo errors that resulted from sampling.

All causal links that were fitted in SEqM occurred between phenotypes recorded on the same TD. This was in line with the assumptions for the simultaneous models, for which simultaneity requires instantaneous feedback. Recursive models, however, can fit lagged relationships between phenotypes. For instance, SCS on a given TD may influence milk yield on the following (and other) TD. Lagged links (between-period effects) were fitted by $\mathrm{Wu}$ et al. (2007a). Both between-period effects (from milk to SCS and from SCS to milk yield) were shown in their study not to be statistically significant. In addition, fitting between-period effects for many time events (TD), as considered in this study for both within- and between-lactation situations, would result in a large number of possible models.

Fat and protein yield are 2 additional traits that are jointly (with milk and SCS) analyzed in the CTDM. Causal links among all 4 traits on the same TD (and possibly on different TD) could be incorporated in terms of simultaneous and recursive relationships. This would, however, lead to a large number of candidate SEqM models. In addition, relationships between fat (protein) yield and SCS are most likely driven by a correlated response from milk to fat (protein). Significant changes in the pattern of relationships between fat (protein) and SCS in addition to those described by milk-SCS links are therefore not anticipated. Similarly, rankings of animals with respect to EBV for all 4 traits 


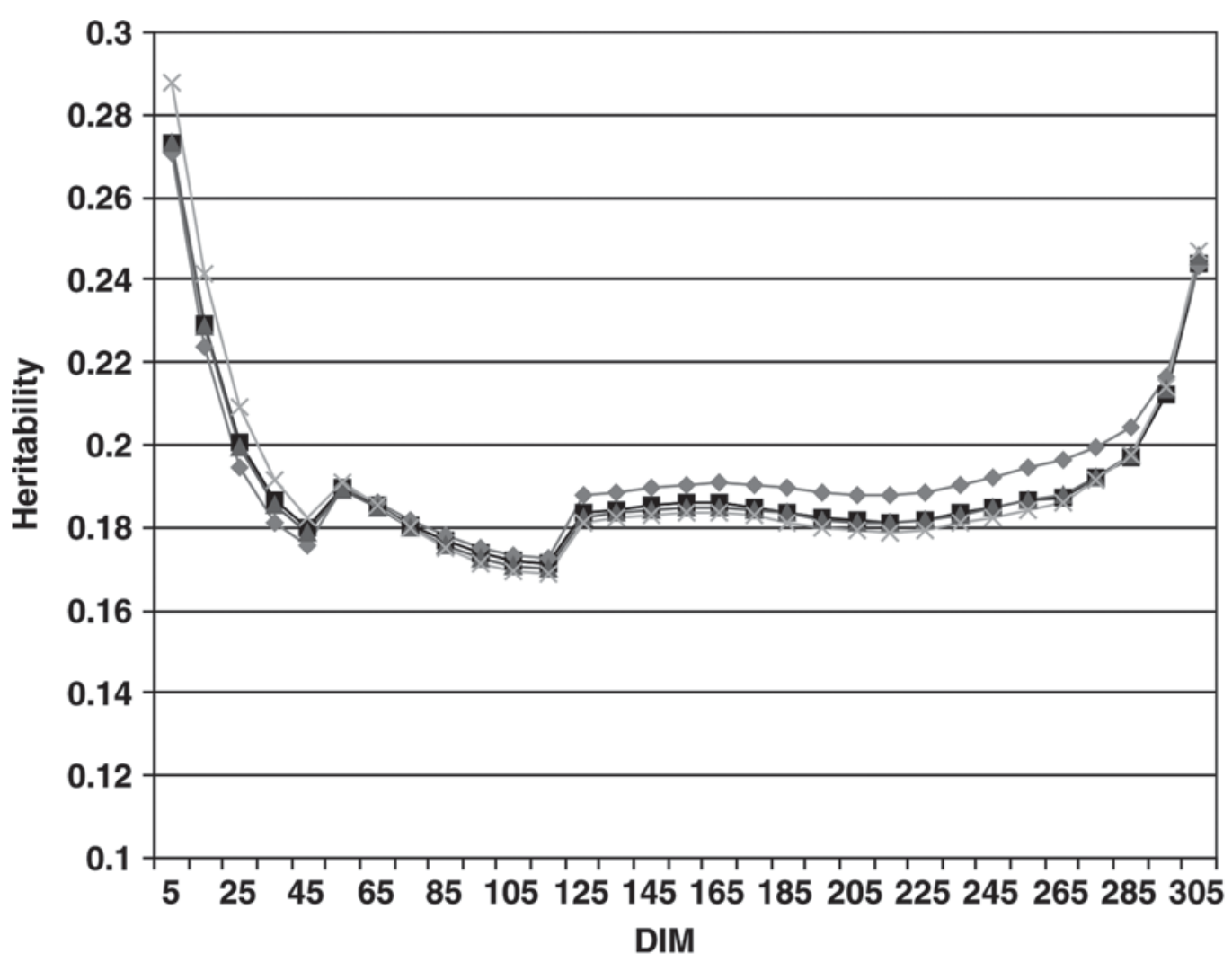

\section{$\rightarrow-$ M-SCS $\rightarrow-M<->S C S$ (het) $\rightarrow$ M<-SCS (het) $\rightarrow$ M->SCS (het)}

Figure 10. Daily heritability of first-lactation SCS for the multiple-trait and heterogeneous models. M-SCS = standard multiple-trait model; $\mathrm{M} \leftrightarrow \mathrm{SCS}$ (het) = heterogeneous simultaneous model; M $\leftarrow$ SCS (het) = model with heterogeneous recursive effect from SCS to milk; M $\rightarrow$ SCS (het) $=$ model with heterogeneous recursive effect from milk to SCS.

should not be different from those for the standard multiple-trait model.

Information on the health status of cows in reference to clinical mastitis was not available in this study. This might have an important effect if relationships between milk yield and SCS depend on the health status of the animal. Finite mixture models have been proposed for analysis of SCS in the absence of information regarding the infection status of cows. Those models assume possible different distributions of SCS for healthy and infectious cows to reflect the fact that SCS might be genetically different traits for these 2 groups (Detilleux and Leroy, 2000). Exploring the relationships between milk and SCS in the framework of finite mixture models, as proposed by Heringstad (2009), might provide new insight into the analysis of these traits.

\section{CONCLUSIONS}

A random regression model with simultaneous relationships between TD milk yield and SCS for the first
3 lactations of Canadian Holstein cows was shown to be superior to a standard multiple-trait model and to models with recursive specifications between traits. A moderate heterogeneous (both across- and withinlactation) negative effect of SCS on milk yield and a smaller positive reciprocal effect of SCS on milk yield were estimated. Estimates of genetic parameters on a daily basis differed between models, whereas rankings of bulls and cows for 305-d milk yield, average daily SCS, and milk lactation persistency remained the same among models. No apparent benefits are expected from fitting causal phenotypic relationships between milk yield and SCS in the random regression TD model for genetic evaluation purposes.

\section{ACKNOWLEDGMENTS}

The authors are grateful to DairyGen (Guelph, Ontario, Canada) and the Natural Science and Engineering Research Council (Ottawa, Ontario, Canada) for their financial support and to CDN (Guelph, Ontario, 
Table 11. Estimates of average breeding values and their standard deviations for bulls $(\mathrm{n}=265)$ and cows $(\mathrm{n}=10,832)$ for combined milk yield, SCS, and lactation persistency, by model

\begin{tabular}{|c|c|c|c|c|c|c|c|c|c|c|c|c|}
\hline Model $^{1}$ & \multicolumn{4}{|c|}{ Milk yield } & \multicolumn{4}{|c|}{ SCS } & \multicolumn{4}{|c|}{ Persistency } \\
\hline M-SCS & 654 & 642 & 522 & 654 & 0.15 & 0.35 & 0.13 & 0.34 & -0.08 & 2.33 & -0.59 & 2.45 \\
\hline $\mathrm{M} \leftrightarrow \mathrm{SCS}$ & 731 & 644 & 593 & 660 & 0.12 & 0.36 & 0.09 & 0.34 & 0.65 & 2.32 & 0.05 & 2.44 \\
\hline $\mathrm{M} \leftarrow \mathrm{SCS}$ & 682 & 645 & 547 & 658 & 0.15 & 0.35 & 0.12 & 0.34 & 0.03 & 2.32 & -0.50 & 2.43 \\
\hline $\mathrm{M} \leftarrow \mathrm{SCS}$ (het) & 665 & 643 & 532 & 656 & 0.20 & 0.35 & 0.17 & 0.34 & -0.11 & 2.31 & -0.61 & 2.43 \\
\hline $\mathrm{M} \rightarrow \mathrm{SCS}$ (het) & 667 & 643 & 534 & 658 & 0.18 & 0.35 & 0.15 & 0.34 & -0.12 & 2.34 & -0.63 & 2.47 \\
\hline
\end{tabular}

${ }^{\mathrm{I}} \mathrm{M}-\mathrm{SCS}=$ standard multiple-trait model; $\mathrm{M} \leftrightarrow \mathrm{SCS}=$ simultaneous model; $\mathrm{M} \leftarrow \mathrm{SCS}=$ model with recursive effect from SCS to milk; $\mathrm{M} \rightarrow$ SCS $=$ model with recursive effect from milk to SCS; M $\leftrightarrow$ SCS (het) = heterogeneous simultaneous model; M $\leftarrow$ SCS (het) $=$ model with heterogeneous recursive effect from SCS to milk; M $\rightarrow$ SCS (het) = model with heterogeneous recursive effect from milk to SCS.

Canada) for providing the data. Comments from Daniel Gianola, Gustavo de los Campos, and Xiao-Lin (Nic) $\mathrm{Wu}$ of the University of Wisconsin-Madison are appreciated with thanks.

\section{REFERENCES}

Bohmanova, J., F. Miglior, J. Jamrozik, I. Misztal, and P. G. Sullivan. 2008. Comparison of random regression models with Legendre polynomials and linear splines for production traits and somatic cell score of Canadian Holstein cows. J. Dairy Sci. 91:36273638 .

de los Campos, G., D. Gianola, and B. Heringstad. 2006. A structural equation model for describing relationships between somatic cell score and milk yield in first-lactation dairy cows. J. Dairy Sci. 89:4445-4455.

Detilleux, J., and P. J. Leroy. 2000. Application of a mixed normal mixture model for the estimation of mastitis-related parameters. J. Dairy Sci. 83:2341-2349.

Dürr, J. W., R. I. Cue, H. G. Monardes, J. Moreo-Mendez, and K. Wade. 2008. Milk losses associated with somatic cell count per breed, parity and stage of lactation in Canadian dairy cattle. Livest. Sci. 117:225-232.

Gianola, D., and D. Sorensen. 2004. Quantitative genetic models for describing simultaneous and recursive relationships between phenotypes. Genetics 167:1407-1424.

Heringstad, B. 2009. Structural equation models in animal breeding. Symp. Stat. Genet. Livest. Post-Genomic Era, Madison, WI.
http://dysci.wisc.edu/sglpage/pdf/Heringstad.pdf Accessed Dec. $11,2009$.

Jamrozik, J., L. R. Schaeffer, and K. A. Weigel. 2002. Estimates of genetic parameters for single- and multiple-country test-day models. J. Dairy Sci. 85:3131-3141.

Kass, R. E., and A. E. Raftery. 1995. Bayes factors. J. Am. Stat. Assoc. 90:773-795.

Muir, B., G. J. Kistemaker, and B. J. Van Doormall. 2004. Estimates of genetic parameters for the Canadian Test Day Model with Legendre polynomials for Holsteins based on more recent data. A report to the Genetic Evaluation Board, April 2004. http://cgil. uoguelph.ca/dcbgc/Agenda0403/GEB\%20Legendre\%20New\%20 for\%20Holsteins\%20-\%20April\%202004.pdf Accessed Dec. 11, 2009.

Samore, A. B., A. F. Groen, P. J. Boettcher, J. Jamrozik, F. Canavesi, and A. Bagnato. 2008. Genetic correlation patterns among SCS and protein yield in Italian Holstein Friesian population. J. Dairy Sci. 91:4013-4021.

Schaeffer, L. R., J. Jamrozik, G. J. Kistemaker, and B. J. Van Doormall. 2000. Experience with a test-day model. J. Dairy Sci. 83:1135-1144.

Wu, X.-L., B. Heringstad, Y.-M. Chang, G. de los Campos, and D. Gianola. 2007a. Inferring relationships between somatic cell score and milk yield using simultaneous and recursive models. J. Dairy Sci. 90:3508-3521.

Wu, X.-L., B. Heringstad, and D. Gianola. 2007b. Exploring the lagged relationships between mastitis and milk yield in dairy cows using a Bayesian structural equation Gaussian-threshold model. Genet. Sel. Evol. 40:333-357. 